\title{
Women's Voices in Civil Society Organizations: Evidence from a Civil Society Mapping Project in Mali *
}

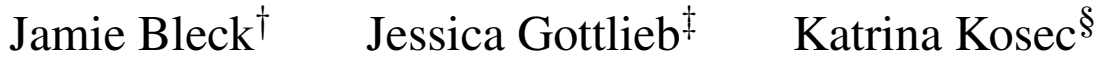 \\ December 25, 2021
}

\begin{abstract}
How does women's engagement in civil society organizations (CSOs) differ from that of men, and what factors predict women's willingness to hold the state accountable? We analyze these questions in the context of rural and urban Mali, leveraging face-to-face data collected as part of a civil society mapping project during February - March 2020 and December 2020, and an in-depth survey conducted with leaders from a randomly-selected subset of these CSOs during January - March 2021. First, we explore the characteristics of women's groups compared to other CSOs. Second, we explore their likelihood of sanctioning a hypothetical corrupt mayor. We use an embedded survey experiment to try to understand these groups' willingness to report on the mayor as well as the payments they expect to receive from the mayor in order to not share information about the mayor's corruption. We find that women in Mali are often highly organized at the local level-frequently in self-help groups or organizations related to gendered economic activities. However, these more economically-focused groupings of Malian women frequently do not translate into civic activity. They are not typically recognized by outside actors as viable CSOs that could incentivize better governance; their strong networks and group infrastructure represent untapped social capital. We also find that CSOs comprised of women have lower informational and technical capacity, especially due to lower levels of political knowledge, and incur a higher cost of sanctioning public officials - though they have greater mobilization capacity. Women's engagement in decision-making in the home also predicts one's CSO being more hierarchical and having greater technical capacity, as well as having higher expected transfers from the mayor-findings that do not vary with respondent or CSO gender.
\end{abstract}

${ }^{*}$ We thank Trevor Lwere and Lindsey Boss for excellent research assistance. This study has received IRB approval from Notre Dame, Protocol Number 20-11-6288 and Texas A\&M University, Protocol Number IRB2020-1291. This study was part-funded by the CGIAR Research Program on Policies, Institutions, and Markets led by IFPRI, the CGIAR Gender Platform, the Helen Kellogg Institute for International Studies and the Office of Research at the University of Notre Dame, and the Scowcroft Institute of International Affairs at the Bush School of Government and Public Service at Texas A\&M University.

${ }^{\dagger}$ Associate Professor, Department of Political Science, University of Notre Dame

$\ddagger$ Associate Professor, Hobby School of Public Affairs, University of Houston

${ }^{\S}$ Senior Research Fellow, International Food Policy Research Institute (IFPRI); Lecturer, Johns Hopkins University 
Turning to the extent to which women involved in CSOs are willing to sanction the state, we find that they are generally less willing than men to sanction, but become more likely when their CSO is less hierarchical, when their technical capacity is higher, and when their political knowledge is greater. However, priming their importance as a CSO (by telling them they were identified by well-connected citizens as being influential) actually reduces sanctioning-perhaps by making them fear that those recommending them will engage in reprisals. Overall, our findings provide useful evidence on the organizational capacity of women and how it is likely to affect the state. 


\section{Introduction}

Civil society organizations play an important role in demanding government accountability. We define civil society organizations as comprising a broad range of groups or associations whose members are engaged in activities outside of the state or explicit partisan networks (Kasfir, 2013). This includes non-governmental organizations (NGOs), voluntary associations, ethnic organizations, religious groups, traditional authorities and their constituents, savings and loans groups, informal, social clubs, unions, and professional organizations. One of their key functions is to monitor and serve as a check on the state's power; they provide a platform for citizens to share information, can build individual and collective efficacy, and provide a coordinating mechanism that spurs collective action (Duncan, 2012). Prior research has stressed the importance of leadership in generating community engagement and shaping local government preferences (Chattopadhyay and Duflo, 2004; Humphreys, Masters and Sandbu, 2006; Jack and Recalde, 2015); if civil society organizations can provide such leadership, they have the potential to improve broad-based public goods provision. Some studies have shown that citizens prefer to contact municipal officials alongside other members of an association rather than individually (Bleck, 2015; Hern, 2019), and thus CSOs can boost collective efficacy.

Since political transitions to multi-party politics in the 1990s, many national-level women's movements have had a substantive effect on debates, policy, and politics around diverse issues such as land rights, opportunities for women's political engagement, gender based violence, and family law (Tripp, 2000, 2004; Tripp and Kang, 2008; Medie, 2013). There is discussion of variation in the "successes" of these movements and counter movements (Kang, 2015). Tripp's (2000) work on the women's movement in Uganda stresses societal autonomy, or the ability of women to re-establish or create state legitimacy (in contrast to co-optation by the state) as key to their success as they sought to redefine gender relations and remove barriers to women flourishing. Kang (2015) stresses the unique domestic context that enables certain types of women's rights policies to become "thinkable."

However, these overt types of political movements represent the minority of women's political 
organization on the continent. Women join associations for diverse reasons. Many more women are involved in economic-based organizations such as rotating credit and savings associations as well as agriculture cooperatives or another type of women's group to secure psychological or emotional support, access to information, or camaraderie (Lasater et al., 2021). For instance, as women seek to earn livelihoods for themselves and their families, they may seek out associational membership, which can help them overcome gendered constraints to entrepreneurship and agricultural markets (Meier zu Selhausen, 2016). Group membership offers other positive benefits such as resource mobilization at times of need, self-esteem, and health outcomes for children (Adams, Madhavan and Simon, 2002; Hägi et al., 2010). For instance, a study of child mortality in Mali, found that among the Fulfulbe (Peuhl) ethnic group women's total, practical, cognitive, and emotional networks were associated with a significant increase in the odds of child survival (Adams, Madhavan and Simon, 2002). Another study from Mali on the incidence of trachoma, a bacterial eye infection, found that there were fewer incidences of the disease in those villages that had women's associations (Hägi et al., 2010). Many of these groups are extremely decentralized and only exert their influence at a very local level. Women's participation in group-based behavioral change communication has also been associated with decreased intimate partner violence (Roy et al., 2019).

While these groups may not have an overt political focus, their autonomy from status quo politics as well as their ability to organize collective action could foster local level political engagement. For instance, in her study of villages at the Mali-Burkina Faso border, Johnson (2021) describes how women's savings and credit associations can facilitate political participation because they build civic skills. Women's organizations, rather than individual women, may be more likely to contact government to advocate for their members and broader public goods and services in their community or to protest or sanction under-performing or corrupt public officials. However, there is variation in groups' ability to foster collective action as well as the skills and resources of individual members. Groups vary in terms of their resources, ability to organize collective action, their leaders' capabilities, and their access to patronage networks (De Jorio, 1997). For instance, (Meier zu Selhausen, 2016)'s study of coffee collectives suggests that women's ability to commit 
to collective action is correlated with duration of membership, access to extension services, more equal intra-household power dynamics, and land ownership.

Despite the importance of civil society organizations, little is known about how women's engagement in civil society organizations (CSOs) differs from that of men, and what factors predict women's willingness to hold the state accountable_-particularly at the local level. On the one hand, women participating in CSOs may be more likely than their male counterparts to hold government accountable and stand up to corruption precisely because they are outside of typical male-dominated patronage networks (societal autonomy (Tripp, 2000)) that would allow them to benefit directly from collusion with the state (i.e., they may not be given transfers or bribes by the state for their support and cooperation). On the other, they may be less likely to hold government accountable because they are more likely to be controlled by and reliant on local power-brokers and their own spouses; that is, they may be less willing to "stir things up" by holding government to account. The types of physical, sexual, symbolic, economic, and psychological violence that female candidates encounter (Krook, 2017) might also be used against active members of women's CSOs. For instance, women-led CSOs may be reluctant to speak out against the powerful or status-quo norms due to fear that adversaries will spread rumors about them in attempts to dampen their credibility. ${ }^{1}$

This paper tackles four related questions about women's association and governance in Mali. First, what do most women's associations in Mali look like, and how do they tend to vary in their organization, functioning, and capacity as compared to men's or mixed gender groups? This research sheds light on such variation in rural and urban Mali using two datasets-one covering 4,061 CSOs but providing briefer information, and another surveying leaders of a subset of 1,014 of these CSOs—-to provide a gendered characterization of CSOs in Mali.

Second, how does the willingness of women's groups to sanction a municipal official who misuses public funds compare to men's groups? Our more comprehensive survey of CSO leaders allows us to examine how gender predicts key features of how CSOs operate, and their propensity

\footnotetext{
${ }^{1}$ In their study of candidates in Malawi, Clayton et al. (2020) found that female candidates (and not their male peers) faced this type of gender-based defamation.
} 
to sanction a hypothetical instance of mayoral corruption conveyed via a vignette, as well as how it affects the transfer payment they think they could elicit from the mayor in exchange for failing to sanction the corruption.

Third, what characteristics of women's organizations predict their willingness to report on a poorly-performing mayor? We use our detailed dataset to consider how women's involvement in decision-making in the home predicts the types of CSOs in which they participate, their likelihood of sanctioning hypothetical mayoral corruption, and their expected transfers from the mayor for remaining quiet.

Finally, we examine how characteristics the environment in which CSOs operate (which are randomly assigned via descriptions in different versions of the vignette) affect their likelihood of sanctioning or of being offered a transfer from the mayor in exchange for not sanctioning, and how this contrasts with characteristics predicting sanctioning for male CSOs. The particular features we experimentally alter include whether or not the CSO is told that well-connected citizens identified their CSO as being influential, whether they believe their role in overseeing the mayor will be short term (1 year) or last for the full period of the program (described as being 5 years), and whether they are told that they will sanction annonymously or not.

Our initial data collection effort was motivated by the fact that there is no existing register of CSOs in Mali, and any that exists would exclude less formal organizations that may still have coordination and mobilization capacities of interest. We thus were motivated to "crowd-source" a list of CSOs from informed local actors. The resulting broad and representative group of actors additionally improves the external validity of our results. The second dataset is comprised of data from interviewing leaders from a subset of these CSOs-1,014 in total from 58 communes, spanning regions in the North, South, and Center.

Overall, we find that women in Mali are often highly organized at the local level—frequently in self-help groups or organizations related to gendered economic activities. However, these more economically-focused groupings of Malian women frequently do not translate into civic activity. They are not typically recognized by outside actors as viable CSOs that could incentivize better 
governance; their strong networks and group infrastructure represent untapped social capital. We also find that CSOs comprised of women have lower informational and technical capacity, especially due to lower levels of political knowledge, and incur a higher cost of sanctioning public officialsthough they have greater mobilization capacity. Women's engagement in decision-making in the home also predicts one's CSO being more hierarchical and having greater technical capacity, as well as having higher expected transfers from the mayor-findings that do not vary with respondent or CSO gender. Turning to the extent to which women involved in CSOs are willing to sanction the state, we find that they are generally less willing than men to sanction, but become more likely when their CSO is less hierarchical, when their technical capacity is higher, and when their political knowledge is greater. However, priming their importance as a CSO (by telling them they were identified by well-connected citizens as being influential) actually reduces sanctioning_perhaps by making them fear that those recommending them will engage in reprisals. Overall, our findings provide useful evidence on the organizational capacity of women and how it is likely to affect the state.

The paper is organized as follows. Section 2 provides background information on governance and the role of CSOs in Mali, including the specific role of women-dominated CSOs. We further introduce here a performance-based budgeting program the government anticipates introducing to our study locations that would involve CSOs in overseeing the government. Section 3 provides details on our two main datasets, the key constructs we capture from them and incorporate into indices, and the equations we estimate to better understand women's participation in CSOs. Section 4 presents our main results, while Section 5 concludes with lessons and policy implications.

\section{Background}

\subsection{Governance and CSOs in Mali}

Mali is a weak state in West Africa, which made a transition to multi-party electoral competition in 1992. It suffered two recent coup d'etats in the democratic era —in 2012 and in 2020 — and has 
suffered a protracted rebellion. ${ }^{2}$ This "democratic" period has been characterized by freedom of association, and Mali has witnessed a proliferation of civil society organizations over the last 30 years. Civil society is composed of a diverse group of organizations including aid-funded NGOs, but also religious associations, self-help groups, and other types of voluntary associations.

We study the relationship between civil society and Mali's lowest level of decentralized political authority, the commune government (particularly the commune mayor). Since 1999, local government councilors and mayors have been elected with five-year mandates in Mali's 703 rural and urban communes. Commune policy is made by the council and executed by the mayor. Councils receive about $\$ 50,000$ per year for use on community development projects from the Agence Nationale d'Investissement des Collectivités Territoriales (ANICT), which represents the largest share of their budget. Communes include an average of 18 different villages, and these project funds typically allow them to select one village in which to build a community development project per annum. Mayors are typically elected every five years and govern municipalities alongside an elected local council of 11 to 45 members depending on population size. Councils are responsible for collecting taxes and providing some basic services, primarily in the areas of primary health and education, sanitation, water, and interior roads. The performance of the mayor's office falls under the oversight of an appointed local prefect.

Mali continues to hold regular elections, but turnout and voting have been constrained by insecurity in some locations. Local communities in Mali face significant infrastructure, governance, and security challenges. Despite the presence of thousands of foreign troops, much of Malian territory is occupied by insurgent groups (including jihadists), inter communal violence, and banditry.

Despite insecurity, municipal offices continue to administer funds. Many of these transfers have some degree of leakage. An audit by the European Commission states that $90 \%$ of inter-

\footnotetext{
${ }^{2}$ Both coups came in response to perceptions of poor governance, and the government's management of insurgency in the North, and later, Center of the country. See (Wing, 2013) for a full account of the 2012 coup. Most recently, in August 2020, the elected government was overthrown by a military coup after weeks of popular protests against corruption and growing insecurity.
} 
governmental transfers to mayors are spent with corruption. ${ }^{3}$

Regular elections fail to discipline mayors in Mali, at least on the dimension of public goods and services. Limited voter information and low expectations about candidate performance weaken electoral mechanisms of accountability (Gottlieb, 2016a). High levels of collusion between local elites from different parties additionally reduces incentives for leadership to be responsive to constituents (Gottlieb, 2015). And, an environment of weak parties and low transparency disrupts the predicted beneficial effects of political competition on government performance: competition has even been shown to have a negative relationship with public goods provision (Gottlieb and Kosec, 2019).

Local mayors may still be responsive to constituents, but the welfare distribution or mechanisms of "accountability" are likely to happen through informal channels that are less legible to outside observers. ${ }^{4}$ Civil society organizations may use informal tactics such as shaming, protests, or threats to withhold support from a voting bloc in order to try to influence the mayor. Instead of investing public funds in the production of club goods or broad-based service provision, candidates may respond to these informal "accountability pressures" by investing in the provision of targeted goods to clientelist networks (Lindberg, 2010).

\subsection{Women's participation in CSOs in Mali}

Mali provides a useful setting in which to consider the dynamics of gender and CSOs. Mali has had a rich and diverse associational life since the transition to multiparty politics in the early 1990s, including a multitude of women's associations. But as Gottlieb (2016b) shows, women in Mali remain a marginalized social group; both the law and societal norms disadvantage women relative to men (Wing, 2012), and the gender gap in civic participation in Mali is one of the highest in Africa (Logan and Bratton, 2006). Women are confronted with strong patriarchal norms and also lag behind their male peers in their political knowledge and ability to provide a political opinion

\footnotetext{
${ }^{3}$ Fawaz, Ahmad. 2010. External audit of local public investments, 1st annual report. SOCOTEC. Bamako, Mali.

${ }^{4}$ Consistent with (Ekeh, 1975)'s seminal essay, redistribution and responsiveness happen in spheres linked to a "primordial public" distinct from bureaucratic channels.
} 
(Bleck and Michelitch, 2018). Mali ranks 184 th of 189 on the UN's gender inequality index. ${ }^{5}$

In such a setting, women may be unlikely to influence government or hold it to account without a group structure — such as that provided by a CSO — that offers the information and collective agency required to fulfill this role. Johnson (2021)'s study of women's participation in associations found that it is key to their political engagement in village affairs. Indeed, Tripp (2000) notes that gendered divisions of labor, gendered organizational modes, and exclusion of women from political life mean that women have a different relationship with the state, its power, and patronage; because of this, women's organizations are uniquely situated with respect to challenging state patronage practices. In the last two decades, women's movements have asserted their power on the national stage in Mali. Women's rights associations were key proponents of a failed family code reform in 2009 (Schulz, 2003). Protests of mothers and wives of soldiers were key in precipitating the coup against then president Amadou Toumani Toure in 2012. However, we know much less about women's roles at the local level.

\subsection{Planned programming to harness CSOs to hold government accountable}

As one strategy to improve local government performance that does not strictly rely on mechanisms of electoral accountability, the World Bank is currently planning to introduce a Performance Based Financing Initiative (PBF). The Malian Government has also taken steps to adopt aspects of performance-based financing in their inter-governmental transfers. ${ }^{6}$ The World Bank's performancebased financing initiative aims to discipline mayors' spending of public resources by tying a bonus payment to refraining from corruption and increasing access to services.

Consistent with our research interest in understanding how CSOs can serve as a viable check on the state, the World Bank is also interested in incorporating CSOs into their PBF program. One way to do this would be for CSOs to serve as an independent monitor of the production of performance measures - helping to solve a problem inherent in performance-based mechanisms of how to ensure

\footnotetext{
${ }^{5}$ http://hdr.undp.org/en/content/gender-inequality-index-gii

${ }^{6}$ This research project is designed to inform these PBF activities, particularly the ways in which they might engage some civil society actors to engage in monitoring municipal performance
} 
that measures are unbiased and accurate. This would require training to increase CSOs' technical and informational capacity so that they could plausibly deliver an accurate favorable or unfavorable report about the mayor's performance. By providing CSOs with the technical capacity to report (including an audience for that report) as well as information required to assess the mayor's actual performance, the program could employ CSOs as local-level monitors of the mayor's performance.

The PBF program thus constitutes a regime change in institutions of accountability relative to the status quo in Mali. Presently, there is little evidence that voters or interest groups discipline the mayor based on stewardship of local funds or public service provision. Instead, rents from holding public office most likely get shared through networks of locally important elites or groups with connections to the mayor - though data on these patterns are lacking. By contrast, the PBF initiative introduces a new mechanism to discipline mayoral performance along with a new audience for information about the mayor's performance. Civil society groups can report performance to an external referee who has resources to reward (or sanction) the mayor. This changes the dynamics of the local governance regime and we aim to uncover how it changes the relationships between CSOs and local governments.

\section{Data and Methods}

In this section, we first describe our population of interest, including our two-step process for mapping CSOs and then surveying a subset of CSOs' leaders. We then describe the vignette experiment that allowed us to understand leaders' propensity to sanction a hypothetical corrupt mayor, anticipated transfer from this mayor for refraining from sanctioning, and how these vary with particular features of the setup (experimentally altered via the vignette).

\subsection{CSO mapping survey}

Our first dataset comprises male and female respondents spread across rural and urban Mali, interviewed during February - March 2020 and in December 2020 (with a break in the mapping 
during April 2020 - November 2020 due to the covid-19 pandemic). This decentralized, crowdsourced exercise was aimed at identifying the CSOs active at the local level and cataloguing some basic characteristics of these groups, including their membership and type. Our bottom-up approach helped us identify small and informal groups that might not be visible to outside observers but play salient roles in the community. We were also careful to highlight the need to capture women's groups in addition to men's.

The motivation for our mapping exercise is the general lack of available information about the full range of civil society groups that exist in Mali. Many civil society organizations are informal or highly localized and, therefore, less legible to those living outside of their zone of intervention. Indeed, Khemani et al. (2016) underscore the lack of evidence and understanding about the operations and impacts of civil society organizations in hybrid regimes like that of Mali. Our mapping exercise thus draws on the expertise of local interlocutors.

In seeking to complete the initial mapping of civil society groups, we started with a list of the 65 rural communes and 26 urban communes (i.e., cities) selected in late 2019 for a World Bank governance program planning to introduce performance based budgeting (after our surveys were completed). Our partner survey firm in Mali-GISSE ${ }^{7}$ - rated four of these rural communes as impossible to access (due to control by jihadist or other insurgent groups) and ten as very difficult to access due to insurgent control or insecurity, which would pose a threat to enumerator safety, limit the activity of any civil society groups, and/or limit the extent to which respondents could participate in a survey. We thus excluded these areas from our sample. Of the remaining 51 rural communes, we selected 40 rural communes, along with 18 of the 26 urban communes based on where our implementing firm, GISSE, already had enumerators working on the ground. ${ }^{8}$

The selected communes are in 18 cercles (the administrative unit above the commune but below the region, much like a county) and span regions in the north, south, and center of the country_including Gao, Kayes, Koulikoro, Mopti, Segou, Sikasso, and Timbuktu. These areas

\footnotetext{
${ }^{7}$ http://www.gisse.org

${ }^{8}$ This local knowledge helps allay some security concerns as GISSE has ongoing operations in these areas, but the choice was also in part due to cost considerations.
} 
exhibit variation in state infrastructure and political competition, as well as past and current exposure to violence from insurgent groups, militias, intercommunal conflict, and the state.

The selection process for respondents varied slightly between rural and urban areas. For rural areas, we sent enumerators to the chef-lieu (the administrative seat-typically the largest municipality) of each cercle in our sample and asked them to identify eight respondents from the commune(s) of interest. These eight respondents should live in the chef-lieu but hail originally from one of the two most politically or economically influential villages in the commune (typically, the commune seat and/or another economic center). The enumerators then interviewed four respondents from each of these two villages. For urban areas, we had the enumerators divide the city into four geographic parts, or neighborhoods, and select four people from each neighborhood. For each village (for rural areas) or neighborhood (for urban areas), the four respondents identified by the enumerators were to be from different sectors of society. The enumerators were asked to include at least one woman and at least one youth. Further, if the village (neighborhood) was characterized by a significant cleavage (for example, ethnic or religious), they were asked to select one respondent from each side of the cleavage. Finally, selected respondents must have visited the village (neighborhood) at least two times in the last six months.

Overall, 757 respondents were interviewed, of whom 34 percent were female and 66 percent male. Respondents were asked to list up to eight of the most active CSOs currently operating in their commune. The enumerators explained that by active, we mean groups that regularly lobby for the needs of their members or the larger community, organize activities and events, provide public goods for the community (such as labor for construction, guidance and counseling, or defense), or provide support to the most vulnerable in the village (for example, paying school fees or health or transport costs). Respondents were prompted to consider informal CSOs that may serve the same role as more formal CSOs_-for example, grinw (informal discussion groups, usually of young men), musotonw (women's groups), religious groups, associations (youth, returned migrants), unions, and prominent business families. For each reported group, enumerators then gathered key details about their membership and group purpose. 
A few notes on data quality are warranted. Given that the same CSOs were sometimes mentioned by multiple interviewees, we omitted duplicate CSOs when analyzing groups. We did not attempt to validate the existence of groups for the purposes of this exercise- though we will do so subsequently for a sample of them. When there is an umbrella group with confederations of associations, each association is allowed to count as its own CSO—consistent with our interest in less visible, less powerful, smaller, or localized groups in addition to powerful, formal, centralized, and well-known groups.

\subsection{CSO leaders survey}

Next, we used the crowd-sourced list of CSOs to generate a sample of CSOs to include in our CSO leaders' survey. Ultimately, we retained the 18 urban communes (each themselves a cercle- or county-level capital) and then selected 30 of the 40 rural communes based on security considerations (due to budget constraints that did not permit us to collect data from all 40). Within each of these 48 communes, we used block randomization to select 20 or 24 CSOs, respectively. We blocked on CSO gender composition (all male, all female, or mixed) and CSO formality (formal or informal), creating six group types; we then selected at least four CSOs in the commune from each particular group type. The resulting sample of 1,020 CSOs (of which we were successfully able to interview $1,014)$ thus expresses substantial variation within each commune on two of our dimensions of interest - gender composition and formality. See Appendix A for further details.

The goal of the CSO leaders' survey is two-fold. First, we aim to measure several key constructs, outlined in the next sub-section. Second, we were able to include several different versions of a vignette about corruption of a hypothetical mayor to assess intended sanctioning behavior and anticipated transfers from the mayor for failing to sanction.

\subsection{Vignette to ascertain CSO willingness to sanction and expected transfers from the mayor}

Following the measurement of these characteristics of CSOs, we introduce a vignette that allows us to subsequently measure key outcomes of interest including willingness to sanction a mayor 
who has acted corruptly and the CSOs' anticipated transfer from the mayor. The vignette poses a hypothetical scenario that informs the participant of a new program, to take place over a period of five years, that closely resembles the World Bank's forthcoming performance-based funding initiative described in Section 2.3. That is, in each of the five years, the mayor will be eligible for a bonus payment if they are found to have used inter-governmental transfers ethically and without corruption. The vignette then informs the respondent CSO that they have been selected to serve as an additional monitor of the mayor's use of funds. This role gives them access to information about the funds that were received and what they were supposed to be spent on - enabling them to evaluate whether funds were spent as intended.

The vignette then introduces a newly elected, hypothetical mayor that misuses the funds in the first year. The CSO, in their new role as monitor, can decide to submit either a negative or positive report. The trade-offs are clearly stated: a negative report decreases the likelihood that the commune will get a performance bonus but at the same time could increase the likelihood that the mayor behaves well in a future period.

We randomly vary three features of the vignette. First, we randomly assigned whether the CSO role as monitor, and subsequent access to information, is a one-year designation for that year or will endure the full five years of the program (Duration Treatment). Second, we randomly assigned whether we inform the CSO that their report will be anonymous or do not do so (Anonymity Treatment). We use a two-by-two factorial design with four equally-sized experimental groups (of 255 CSOs each) reflecting the four combinations of the two versions of the vignette.

We also implement a third experimental manipulation for which we randomly assign groups of respondents to either receive a self-confidence boost achieved by priming them to feel that their civil society group is important (T1) or not. The self-confidence boost takes the form of a script read to participants prior to the introduction of the vignette, saying they were selected by well-connected citizens from their area as one of the most influential CSOs operating in their locality, which is why we are eager to hear their views. The goal of $\mathrm{T} 1$ is to make respondents feel that their group is relatively important — which may trigger a sense of duty and obligation to represent citizens well as 
a monitor.

The exact wordings of all vignettes appear in Appendix C. These were audio-recorded in local languages to ensure homogeneity of treatment within the same condition and to make the treatments as strong as possible. We worked with our local partner to identify actors and ways of explaining the vignette in common parlance that would be both comprehensible and credible to the respondent. We reviewed the local language translations in Bamana to ensure clarity and also to ensure that corruption was being portrayed with as little stigma as possible, since our assumption is that it can fuel alternative channels of distribution.

\subsection{Measurable characteristics of CSOs}

We pre-specified batteries of questions we would use to measure a number of different characteristics of CSOs. We create an additive index for each construct by taking the mean of non-missing values of standardized versions of each variable. Before they enter the index, the component variables with categorical response choices were re-coded where necessary to ensure a monotonic relationship in the desired direction between that variable's numerical value and the construct being measured. In some cases, variables were dropped from the index if there was no direct substantive connection between the question in the battery and the outcome of interest (e.g., some questions were asked as background rather than direct proxies for the construct of interest, and in other cases we identified variables that were unexpectedly negatively correlated with all other variables in the index). Below, we summarize each index and its component variables (see Appendix $\mathrm{C}$ for the survey questions and full range of responses).

The Hierarchy Index measures how hierarchical the CSO is, with higher values indicating more hierarchical and lower values indicating more egalitarian. It is comprised of constituent variables that measure various expressions of hierarchy: whether the power is distributed across members (more egalitarian) or centralized in the hands of a few (or just one) member, whether a leader can block a group decision (more hierarchical) to whether all members need to agree to block, whether the president or treasurer can withdraw money from a group account by herself (more hierarchical), 
whether the meeting place of the group is the leader's house (more hierarchical), greater share of group members who can influence the group's decisions (more egalitarian), and the extent to which an ordinary member would succeed at influencing the group leaders in case of a disagreement (more egalitarian).

The Embeddedness index captures the capacity of the CSO to impose costs on the mayor (outside the formal PBF mechanism) and thus reap higher informal transfers. Higher values of the index indicate greater embeddedness, and thus greater ability to impose costs on the mayor. It is comprised of constituent variables that measure how often members of the group meet with non-member citizens to share their plans, how long ago the group was founded, the extent to which the group's goals are long-term as opposed to short-term, and the level of citizen awareness of the group's activities.

The Informational Capacity index measures the group's access to information about the mayor's activities, with higher values indicating greater capacity and lower values indicating lower capacity. It comprises constituent variables that measure whether the respondent can correctly name the commune mayor, whether the respondent has the mayor's number, whether the respondent knows which family the mayor comes from, whether the respondent knows the number of seats on the commune council, whether the group has received any funding from the local government over the last two years, if in the last two years the group held meetings with some leaders, how often group members meet with elected officials, whether the group has a point of contact in the local government for when need arises, how the group likely would know if the mayor used part of the public budget and whether the respondent can name two groups that are likely to win government contracts.

The Technical Capacity index measures the group's technical capacity to make a negative report on the mayor's performance, with higher values indicating greater capacity and lower values indicating lower capacity. It is comprised of constituent variables that measure: whether the group has received any funding from a donor in the last 2 years, whether the group is duly registered 
with the state, the percentage of members that can read and write in French, ${ }^{9}$ if the respondent can read and write in French, how often the respondent follows current affairs in French, how often the respondent listens to news about political parties, the importance to the group of working with other CSOs, how ordinary citizens regard the group relative to other CSOs, how often citizens respond to the group's calls to actions, ease with which group can convince respondents to support a policy, an idea or vote for a candidate, ease of mobilizing the group's own members to do an activity outside normal work, ease for the group to reach agreement on collective action,if the group has mobilized its members to attend a town hall meeting in the past year and whether mobilized its members to join a protest in the last year.

The Cost of Social Sanctions index measures the social consequences against the group for giving a negative report against the mayor, with higher values indicating greater social costs of sanctioning and lower values indicating lower social costs of sanctioning. It includes constituent variables that measure the importance of the group's relationship with the mayor to the group's ability to operate, importance of relationship with non-member citizens to the group's ability to operate, the occupation of the wealthiest member of the group, how often the group accounts for public opinion before making decisions, group leader's wealth relative to other CSOs, and wealth of members relative to members of other groups.

While we pre-registered these main indices, an inductive analysis of the component variables led us to create sub-indices for some constructs when the sub-indices appeared to be capturing substantively distinct concepts. Below, we describe the sub-indices and their component variables. In the analysis, we will report results for both main indices and their sub-indices.

The Political knowledge sub-index is a sub-index of the Technical capacity index. This subindex measures the political literacy level of the group's member, with higher values indicating more political knowledge and lower values indicating lower political knowledge. It comprises constituent variables which measure the percentage of members that can read or write in French,

\footnotetext{
${ }^{9}$ In Mali, most citizens communicate in indigenous languages, but French is the official language of the state bureaucracy and often used as a language for news broadcasting by the state or international radio. Many Malian citizens do not speak French.
} 
if the respondent can read or write in French, how often the respondent follows current affairs in French, how often the respondent listens to news about political parties and the importance of working with other CSOs to the group's ability to operate.

The Community Influence sub-index is a sub-index under the Technical capacity index. This sub-index measures the degree of influence that the group has in the community, with higher values indicating greater capacity and lower values indicating lower capacity. It is made up of constituent variables which measure how ordinary citizens regard the respondent's CSO relative to other CSOs, how much ordinary citizens listen and/or respond when respondent's CSO shares information or a call to action, and the ease with which respondent CSOs can convince citizens to support a policy, an idea or vote for a candidate.

The Internal Coordination Capacity sub-index is a sub-index of the Technical Capacity index. It measures a group's ability to mobilize its own members, with higher values indicating greater capacity and lower values indicating lower capacity. It has constituent variables which measure if a group has mobilized its members to attend a town hall meeting or join a protest in the past year, ease for the group to mobilize its own members to do an activity outside normal work, and ease for group members to reach collective agreement on priorities and action.

The Financial vulnerability sub-index is a sub-index of the Social Cost of Sanctioning index. This sub-index measures the level of financial dependence of a CSO, with higher values indicating greater dependence and lower values indicating lower dependence. It has constituent variables which measure the profession of the wealthiest group member, the level of the group leader's wealth relative to other CSOs and wealth levels of group members relative to members of other groups.

The Social dependence on mayor sub-index is a sub-index of the Social Cost of Sanctioning index and it measures the level of dependence of the group on the mayor for its ability to operate, with higher values indicating greater dependence and lower values indicating lower dependence. It has one constituent variable that measures the importance of the relationship with the mayor to the group's ability to operate which is reverse-coded.

The Community dependence sub-index is also a sub-index of the Social Cost of Sanctioning 
index. It measures the degree of dependence of the group on the community for its ability to operate, with higher values indicating greater dependency and lower values indicating lower dependence. It has constituent variables that measure the importance of the relationship with non-member citizens for the group to operate and how often the group accounts for public opinion before making decisions.

We also analyze as outcomes two questions asked post-vignette. The first is the CSO's Willingness to sanction the mayor by producing a negative report, on a scale from 0 to 10 . This could be considered a normatively sensitive item, inducing social desirability bias or an incentive for the respondent to overstate their willingness to sanction the government. While the bias could theoretically go in either direction, our partner administering the CSO survey (GISSE) agreed that the most likely direction of bias would be for CSOs to overstate, assuming that submitting an honest report of corruption (given they were told it occurred) is normatively desirable.

We aimed to overcome this bias by clearly highlighted in the local language translation of the vignette the trade-off that CSOs face when deciding whether or not to sanction the government and to lessen stigma around willingness to receive kickbacks from the mayor. That language recognizes that while a negative report could potentially reduce future sanctioning, a positive report would increase the likelihood that the CSO shares in the spoils of corruption through local level redistribution by the mayor. This is harder to articulate credibly in English since this trade-off is one that rarely gets talked about in development circles by donors given the strong normative resistance to corruption. However, this is a very real trade-off that local CSOs are familiar with, and so we worked with our local partners, including GISSE, to find ways to say this that would make sense and sound credible to CSOs. The question specifically says, "We know there are a lot of considerations related to whether you would make a report on the mayor's performance or not, since that decision could have both costs and benefits for your group. Accounting for this, what is the probability that you would submit a negative performance report?"

A second and related outcome of interest is the Expected transfer price the CSO would receive from the mayor if it entered into a collusive bargain. To get at this, we ask respondents, "Sometimes 
the funds a mayor receives can result in profits for a leader or citizen member of a civil society group. What is the portion of the 5 million CFA (about 9000 USD) bonus that you think the mayor might spend in a way that is personally profitable to you or your members?" In the analyses, we convert the CFA responses to approximate US dollar values using the exchange rate of $550 \mathrm{CFA}$ to $1 \mathrm{USD} \cdot{ }^{10}$ Only $28 \%$ of respondents gave a non-zero response to this question. As a result, we will analyze variation along both the intensive margin, with the continuous variable, as well as the extensive margin, with an indicator of whether the CSO expects a non-zero amount from the mayor.

We consider the values of these constructs and outcomes separately by gender as non-egalitarian gender norms have been consistently shown to matter for civic and political participation in Mali. In particular, we expect that women's groups will perceive a greater cost of sanctioning due to their lower levels of autonomy and higher levels of vulnerability; they may also be sanctioned not only by the community and its leaders, but also by their spouse or other male family members. Furthermore, given women's lower literacy levels and weaker engagement in civic and public affairs, women's groups may naturally lower technical and informational capacity, or expectation that a formal sanction will elicit improved public goods spending.

\subsection{Women's involvement in decision-making index}

Finally, we construct an index which is the mean (where missing data is ignored and thus the mean computed over non-missing variables) of nine dummy variables for women participating in key intra-household decisions or decision-making processes. These nine decisions include sending children to school, selecting a marriage partner for the son or daughter, the husband taking on another wife, how a woman spends her money if she earns it herself, buying expensive items, discussions on community issues, the work a female member of the household can do, borrowing money from others, and saving in the household. We standardize this mean such that the resulting index, which we call our Women's Decision-making Index, has mean 0 and standard deviation 1.

\footnotetext{
${ }^{10}$ This is between the February 2021 (542 CFA to 1 USD) and March 2021 (551 CFA to 1 USD) average exchange rates, which prevailed during the time of our data collection (https://www.exchangerates.org.uk/USD-XOF-spotexchange-rates-history-2021.html)
} 
While this index only measures the household power of female leaders, it serves as a proxy for human capital within the leadership of the group.

\subsection{Econometric specification}

We utilize three different ordinary least squares (OLS) econometric specifications. The first tests how women's involvement in decision-making (described in sub-section 3.5) is associated with each of various CSO characteristics and with women's likelihood of sanctioning a corrupt mayor and the transfer they would expect from the mayor for staying quiet (all described in sub-section 3.4). Here, we examine the extent to which women's agency within the household predicts the nature of her participation in CSOs beyond the household. Specifically, it estimates specifications of the following form:

$$
O_{i}=\alpha_{0}+\alpha_{1} D_{i}+\alpha_{2} D_{i} \times M_{i}+\alpha_{3} M_{i}+\varepsilon_{i}
$$

where $O_{i}$ is an outcome for CSO leader $i, D_{i}$ is our women's decision-making index, and $M_{i}$ is a dummy for the respondent being male. The coefficient $\alpha_{1}$ measures whether decision-making authority in the home matters for the outcomes of women respondents, while the coefficient $\alpha_{2}$ measures whether or not it matters significantly more for women respondents compared to men.

Our second specification tests the extent to which key CSO characteristics predict the likelihood of sanctioning a hypothetical corrupt mayor, and the transfer from the mayor expected for staying quiet, flexibly allowing the effects of each to vary with gender. Specifically, we estimate specifications of the following form:

$$
\begin{aligned}
S_{i}=\beta_{0}+\beta_{1} H_{i}+\beta_{2} E_{i}+\beta_{3} I_{i}+\beta_{4} T_{i}+\beta_{5} C_{i}+\beta_{6} H_{i} \times M_{i} & +\beta_{7} E_{i} \times M_{i}+\beta_{8} I_{i} \times M_{i}+\beta_{9} T_{i} \\
& \times M_{i}+\beta_{10} C_{i} \times M_{i}+\beta_{11} M_{i}+u_{i}
\end{aligned}
$$

where $S_{i}$ is a sanctioning or transfer-related outcome of interest. The independent variables refer to the key constructs described in 3.4. $H_{i}$ is the hierarchy index; $E_{i}$ is the embeddedness index; $I_{i}$ 
is the informational capacity index; $N_{i}$ is the technical capacity index; and $C_{i}$ is the social cost of sanctioning index. We also estimate specifications that include, in lieu of $N_{i}$ and $C_{i}$, the vectors of sub-indices that correspond to each, also described in sub-section 3.4.

Finally, our third specification tests the causal impacts of our experimental vignette treatments, flexibly allowing their impacts to vary by gender. Specifically, we estimate the following model:

$$
S_{i}=\gamma_{0}+\gamma_{1} T_{i}+\gamma_{2} T_{i} \times M_{i}+\gamma_{3} M_{i}+\mu_{i}
$$

where $T_{i}$ is an indicator variable for an experimental treatment-either T1, T2, or T3 (we consider the impacts of each one at a time).

In equation 1 , we take $M_{i}$ to be a dummy for CSO leader's own gender being male, as this analysis aims to understand what individual-level characteristics-including one's gender and how decisions are made in their own household-predict about the types of CSOs in which they engage, and how they personally feel about sanctioning a corrupt mayor, or how much they would expect a corrupt mayor to transfer to them to avoid being sanctioned. In equations 2 and 2, in contrast, we are interested in both individual-level and group-level factors that might influence sanctioning behavior; as such, we run analyses both when $M_{i}$ is a dummy for the respondent being male and when it is a dummy for the group not being a women's group, which we define as a group in which 75 percent or more of members are women.

\section{Results}

\subsection{Analysis of CSO mapping survey}

\subsubsection{Gender composition of CSOs}

The 757 respondents named a total of 4,893 CSOs_-an average of 6.5 CSOs per respondent. As Figure 1 shows, 1,179 of these were women's CSOs (comprising entirely female members), 738 were men's CSOs (comprising entirely male members), and 2,144 were mixed-gender CSOs 
Figure 1: Number of CSOs named by gender composition of members

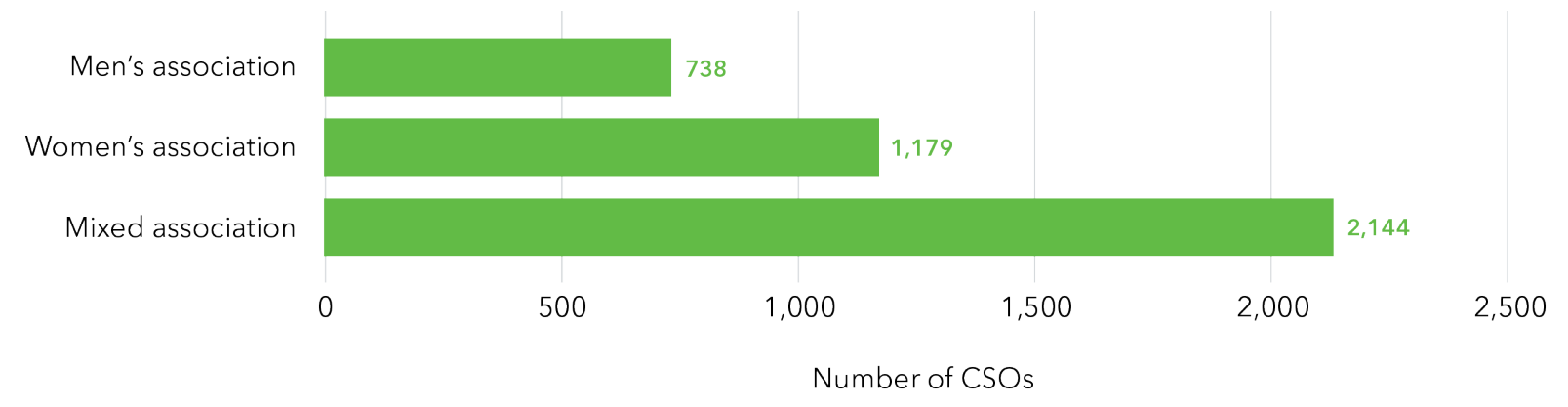

(comprising male and female members, and led by either gender).

That women's CSOs are so plentiful—indeed, more plentiful than men's—is consistent with women having substantial coordinating capacity and social capital. It may also indicate a greater need for them to coordinate in women-only arenas either because they have unique needs and preferences or because they feel constrained in mixed-gender settings. In any case, the question remains of whether women can translate that coordinating capacity into effective civic and political engagement; our survey captures the former, but not the latter. Additionally, our CSO mapping exercise did not indicate, for mixed-gender CSOs, the share of membership that was female, or whether the organization was woman-led. To the extent that men dominate mixed-gender organizations, it may be the case that men dominate CSO activity. Nonetheless, it is clear that women have tangible capacity in civil society in Mali—both through their own CSOs and through mixed-gender associations.

A natural question is whether respondents were more likely to identify CSOs matching their own gender. Our procedure for selecting respondents mandated that at least 25 percent were female and our final sample was 34 percent female. Respondents were then asked to list up to eight total CSOs. To the extent that respondents' social networks include more individuals of their own gender, they may be more aware of civil groups dominated by members of their own gender. Further, individuals' relatively greater knowledge of the activities of groups sharing their gender may lead them to prioritize listing those organizations over groups of the other gender about whose activities 
Figure 2: Gender composition of CSOs named by respondents' gender

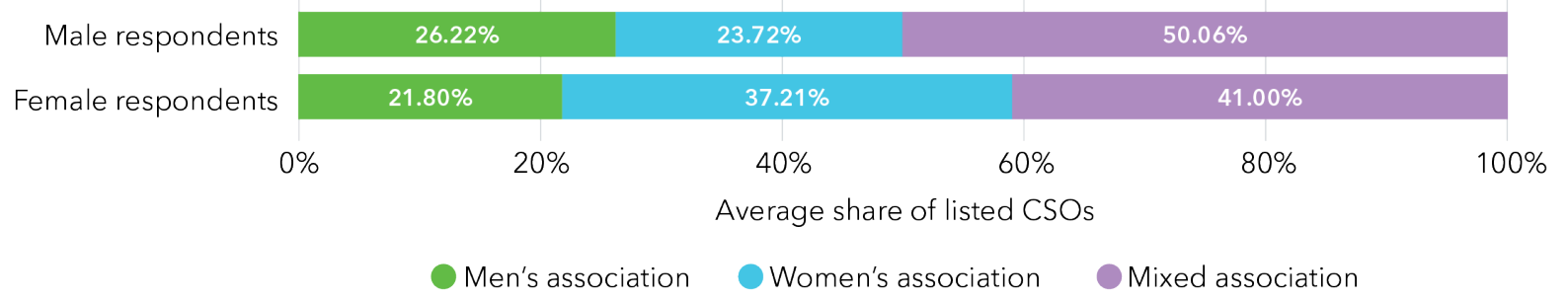

they are less aware.

We indeed find that women are relatively more likely to list women's CSOs, while men are relatively more likely to list men's CSOs (Figure 2). Specifically, women's CSOs comprise 37 percent of the CSOs mentioned by female respondents, but only 24 percent of those mentioned by male respondents. Likewise, men's CSOs comprise 26 percent of the CSOs mentioned by male respondents, but only 22 percent of those mentioned by female respondents. Men are also relatively more likely to list mixed-gender CSOs, which comprise a full 50 percent of those they listed, compared to only 41 percent for women. We do note the possibility that there are organizations that women consider men's groups, while men consider them mixed-gender groups due to greater awareness of their activities and membership_possibly involving a few women. Overall, however, it is somewhat remarkable that there is not more bias in identifying CSOs; men seem aware of women's groups, and women seem aware of men's groups.

\subsubsection{Formality and age orientation of CSOs}

Considering CSOs of varying gender compositions, we next looked at the degree of formality of the CSO, and whether it was oriented toward youth members or had a more mixed or older membership. We consider groups as formal when they are registered with the state (such as the case with unions, NGOs, and other official groups). Group formality can be important for visibility to others as well as group organization; formal CSOs are those with which government, NGOs, and donors often collaborate, and they might have access to more funds and opportunities to engage with 
Figure 3: Formality of CSOs by gender composition of members

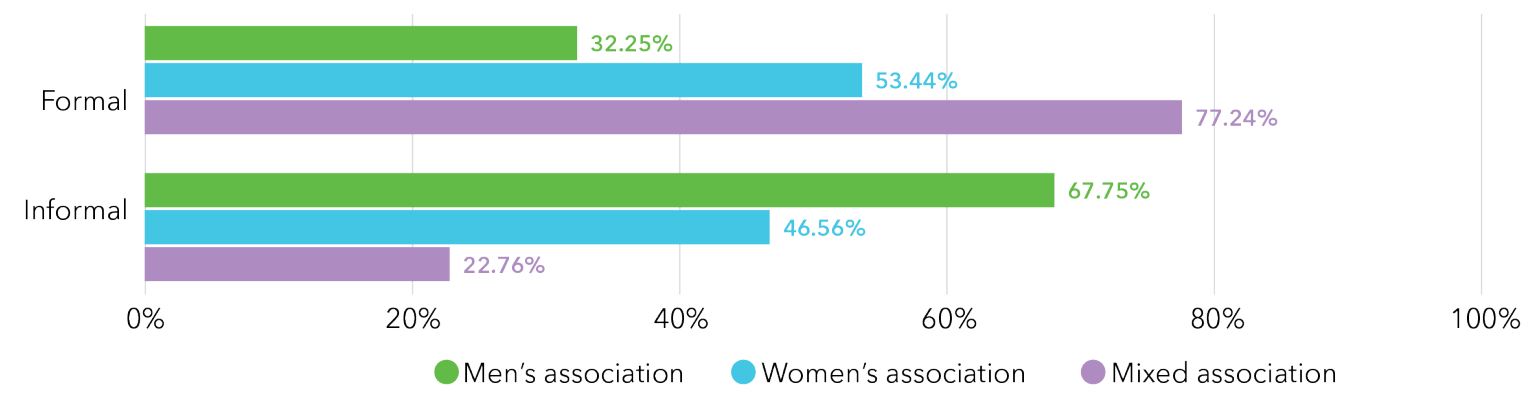

these actors. Further, information about informal CSOs and their activities may be less available to citizens. Informal groups may nonetheless play important roles for their members or society and have significant influence over certain segments of society. For instance, surveys of informal, tea-drinking clubs (grinw) and their members in Bamako and Mopti found that 45 percent of members claimed to have found a job or business opportunity through membership and 69 percent of these organizations claimed to engage in public goods provision for their communities (Bleck et al. 2017). Due to their informality and fewer formal engagements with government, NGOs, and donors, informal groups may be more autonomous and independent, making them better poised to defend individual citizens' interests.

We find that all-female CSOs are more likely to be formal than are all-male CSOs (Figure 3). Specifically, while all-female CSOs are relatively evenly split between formal (53 percent) and informal (47 percent), all-male CSOs are over twice as likely to be informal (68 percent) than formal (32 percent). Further, mixed-gender associations are the most likely to be formal (over 77 percent).

While one might expect women's groups to be more likely to be informal relative to men's groups, two features of the Malian context can help explain the inverse pattern we see in the data. First, a common type of group in our data, grinw, primarily comprises young men and is almost always informal. Second, Mali has maintained very high levels of freedom of association and openness with respect to the creation of civil society groups since democratization in 1991, so the barrier to creating formal groups is not high, and we do not have reason to believe barriers would 
Figure 4: Youth focus of CSOs by gender composition of members

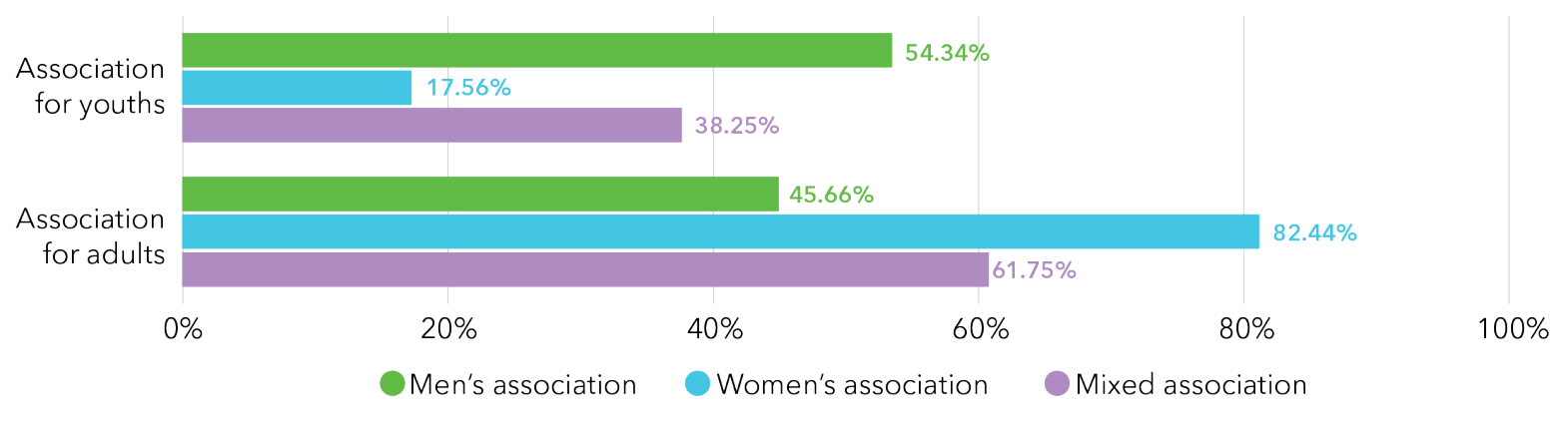

be higher for women. Instead, gender norms are more likely to apply to the activities these groups would undertake, or what would be seen as socially acceptable, as we will see in the next section.

Another key characteristic of CSOs is their age orientation. Specifically, we considered whether they are youth-oriented or not (Figure 4). We find that all-male CSOs are the most likely to be youth organizations (54 percent), followed by mixed-gender CSOs (38 percent); all-female CSOs are much less commonly youth-focused (only 18 percent). Male youth, in contrast, have substantial opportunities for civic engagement, both through mixed-gender and all-male groups.

\subsubsection{CSO purpose}

Beyond formality and age orientation, the intended function or purpose of a CSO greatly influences its activities and engagement with government, NGOs, and donors. We asked an open-ended question about the primary activity of each CSO and were able to group CSOs according to five purposes: economic, public services, civic-political, social, and other. Overall, economic groups dominate, comprising over 40 percent of total groups, followed by public service groups, which comprise about 30 percent (Figure 5). Both male and female respondents named similar numbers of groups with different purposes, suggesting similar familiarity with groups across domains. Women mentioned economic and social groups slightly more often than did men, while men mentioned civic-political and public service groups slightly more often than did women.

For each of the five purpose categories, there are more all-female CSOs with that purpose 
Figure 5: Number of CSOs of different purposes

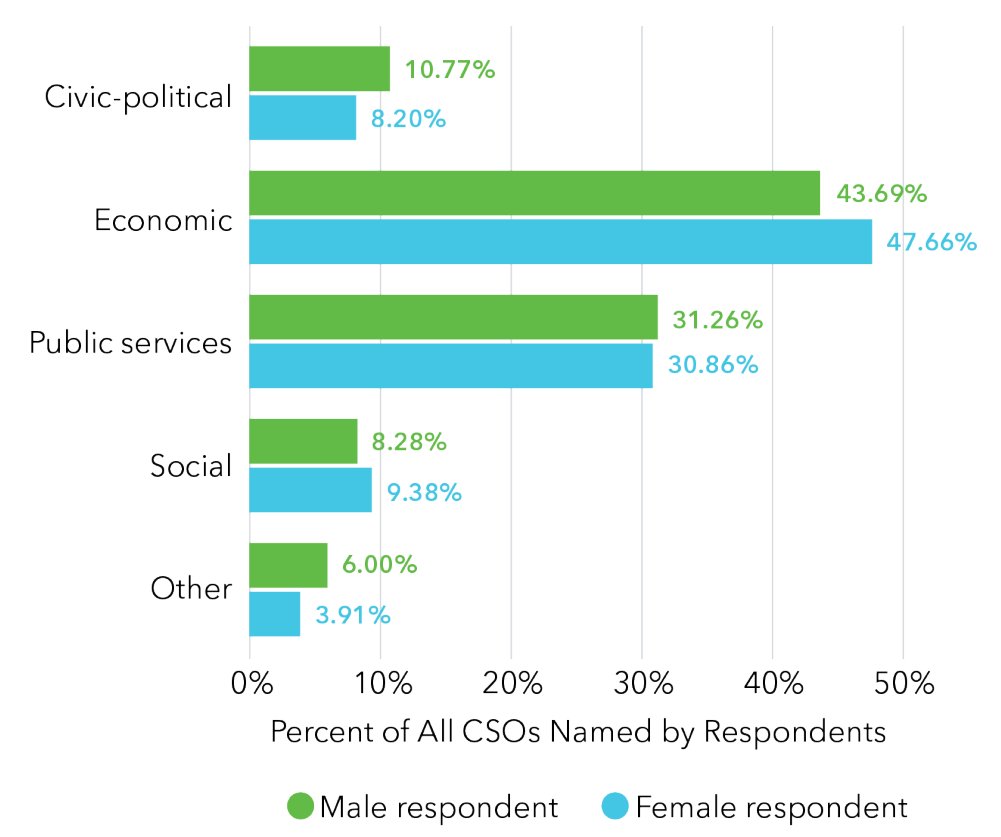

Figure 6: Gender composition by broad purpose of CSOs

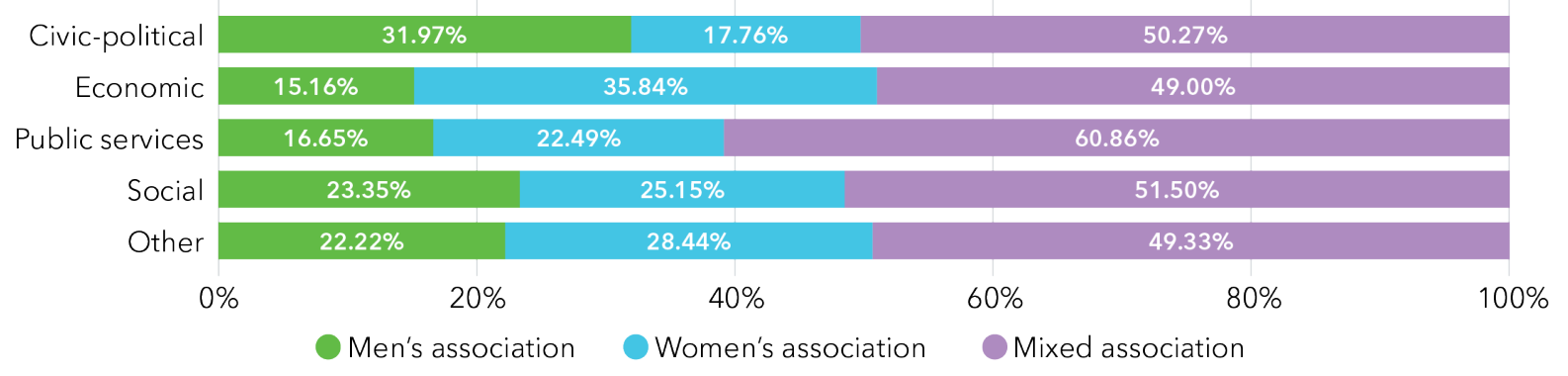

than all-male CSOs, with one exception: for civic-political groups, 32 percent are men's CSOs, while only 18 percent are women's CSOs, and the remaining half are mixed-gender CSOs (Figure 6). Women's groups are less likely to engage in politics, which mirrors other findings that point to a pervasive gender gap in nearly all forms of political participation (Logan and Bratton, 2006), political knowledge, and political opinions (Bleck and Michelitch, 2018). For every group purpose, however, at least 49 percent of CSOs are mixed-gender (mixed-gender CSOs are most common in the public service category). Again, we find strong evidence that women have substantial coordinating capacity and social capital —and this spans groups of all purposes. 
Figure 7: Gender composition of economic-related CSOs

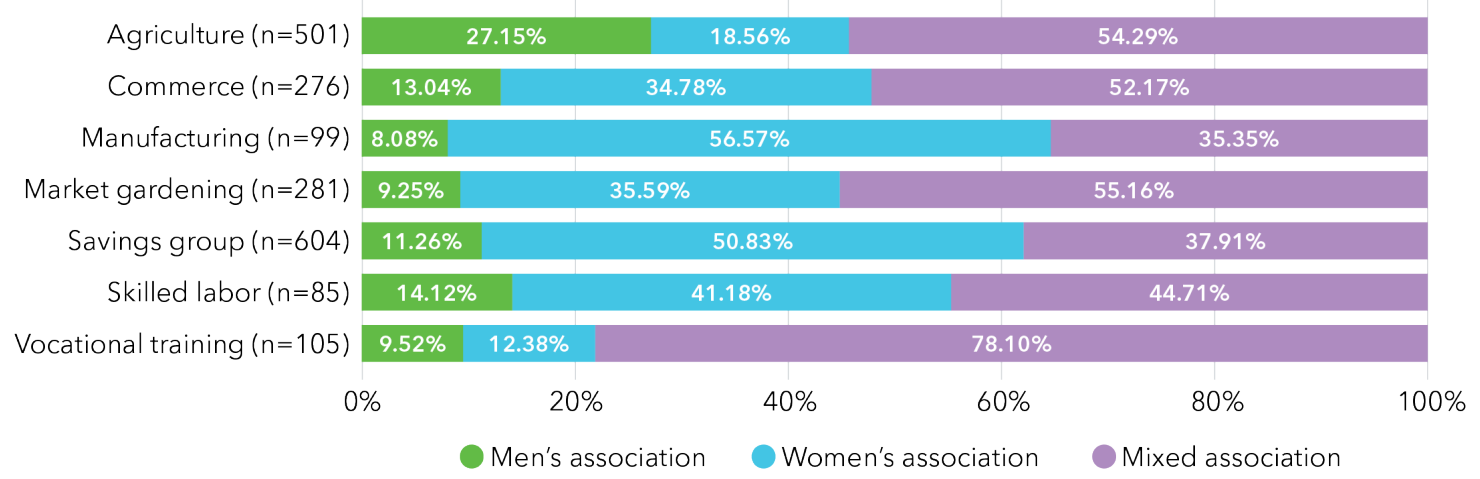

The most common types of associations are economic and public service CSOs. For each of these main types, however, CSOs engage in a variety of different activities. For economic CSOs, these include agriculture, commerce, manufacturing, market gardening, savings groups, skilled labor, and vocational training. All-female CSOs are more common than all-male CSOs in certain key areas like manufacturing, savings groups, skilled labor, and market gardening (Figure 7). Agriculture is the only area where men's groups are more common than women's groups.

For public service-related CSOs, activities include community development, education, environmental conservation, healthcare, peace and conflict resolution, road maintenance, sanitation, security, and social protection. All-women's groups are more plentiful than are all-men's groups in most of these areas, with the exception of peace and conflict resolution, road maintenance, and security (Figure 8). For CSOs of all purposes, at least 48 percent are mixed-gender, with mixed-gender groups most plentiful in the areas of healthcare and community development. 
Figure 8: Gender composition of public service-related CSOs

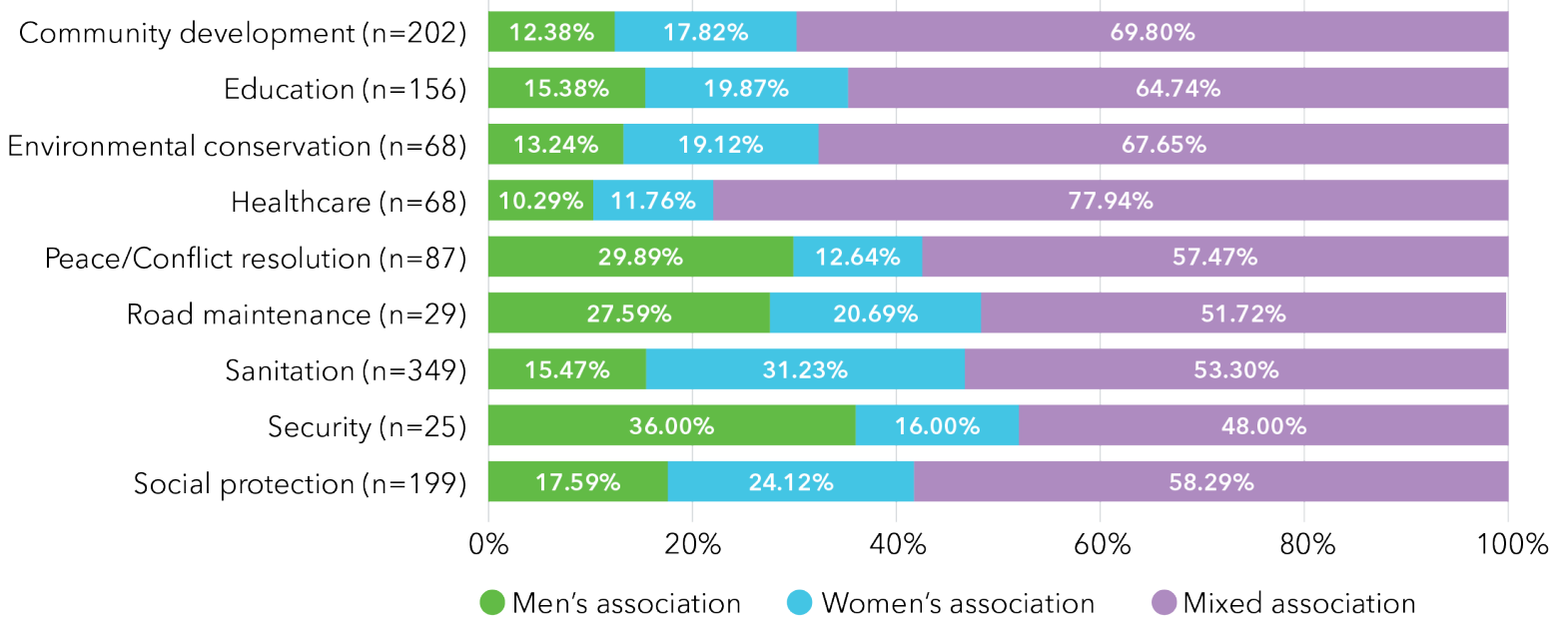

\subsection{Analysis of CSO leaders survey}

Our CSO leader survey provides distinct and more detailed data provided by the leaders of a subset of the CSOs analyzed in the previous section. Analyzing these data, we first consider the very broad question of how groups dominated by women (greater than $75 \%$ of members) differ from others in terms of measurable CSO characteristics captured by our indices (hierarchy, embeddedness, informational capacity, technical capacity, and social cost of sanctioning). Table 1 presents these results with our main indices (column 1) and with our main indices for those constructs which lack sub-indices and sub-indices otherwise (column 2).

We see that women's groups have consistently lower levels of both informational and technical capacity than do other groups (especially with respect to political knowledge)—reflecting a weak structural position in the community. While women's groups have the lowest levels of political knowledge, they have the highest levels of mobilization capacity, likely related to their thick networks and associations among women in the community. There is also some evidence that women's groups tend to be more hierarchical compared to groups not dominated ( $75 \%$ or more) by women. This complements our previous analysis of our CSO mapping dataset by showing that women's CSOs differ qualitative from others in highly measureable ways. 
Table 1: Regression of having 75 percent or more women in CSO on main indices and sub-indices

\begin{tabular}{|c|c|c|}
\hline & Main indices & Sub-indices \\
\hline Hierarchy Index & $\begin{array}{c}0.034 \\
(0.029)\end{array}$ & $\begin{array}{l}0.050^{+} \\
(0.029)\end{array}$ \\
\hline Embeddedness Index & $\begin{array}{l}-0.002 \\
(0.026)\end{array}$ & $\begin{array}{l}-0.002 \\
(0.027)\end{array}$ \\
\hline Informational Capacity Index & $\begin{array}{c}-0.140^{* * *} \\
(0.034)\end{array}$ & $\begin{array}{c}-0.123^{* * *} \\
(0.034)\end{array}$ \\
\hline Technical Capacity Index & $\begin{array}{c}-0.071^{+} \\
(0.037)\end{array}$ & \\
\hline Social Cost of Sanctioning Index & $\begin{array}{l}0.056^{+} \\
(0.030)\end{array}$ & \\
\hline Political Knowledge Sub-Index & & $\begin{array}{c}-0.160^{* * *} \\
(0.025)\end{array}$ \\
\hline Community Influence Sub-Index & & $\begin{array}{c}0.033 \\
(0.024)\end{array}$ \\
\hline Mobilization Capacity Sub-index & & $\begin{array}{l}0.080^{* *} \\
(0.027)\end{array}$ \\
\hline Financial Vulnerability Sub-index & & $\begin{array}{c}0.034 \\
(0.021)\end{array}$ \\
\hline Mayor Dependence Sub-index & & $\begin{array}{c}0.024 \\
(0.016)\end{array}$ \\
\hline Community Dependence Sub-index & & $\begin{array}{c}-0.036^{+} \\
(0.021)\end{array}$ \\
\hline Constant & $\begin{array}{c}0.358^{* * *} \\
(0.015)\end{array}$ & $\begin{array}{c}0.358^{* * *} \\
(0.014)\end{array}$ \\
\hline Observations & 1014 & 1014 \\
\hline
\end{tabular}




\subsubsection{Women's decision-making in the home and CSO-level outcomes}

We next analyze the extent to which women's ability to make decisions in the respondent's home is associated with particular CSO characteristics. That is, are individuals-male or female-who come from more egalitarian households more likely to select into leading particular types of groups? Table 2 shows for our main indices and our two sanction-related outcomes, and Table 3 shows for our sub-indces, that this is indeed the case. Such individuals tend to lead more hierarchical groups with higher technical capacity (both in terms of political knowledge and mobilization capacity). They also tend to be less financially vulnerable, more dependent on the mayor, and able to extract a larger transfer from the mayor.

Table 2: Regressions of CSO characteristics and sanction-related outcomes on women's decisionmaking power index

\begin{tabular}{lccccccc}
\hline & Hierarchy & Embed. & Info. Cap. & Tech. Cap. & Soc. Costs & Sanction & Trans. Size \\
\hline Women's decision-making index & $0.04^{+}$ & 0.03 & -0.02 & $0.03^{+}$ & -0.02 & -0.07 & $158.37^{* * *}$ \\
& $(0.02)$ & $(0.02)$ & $(0.02)$ & $(0.02)$ & $(0.02)$ & $(0.09)$ & $(44.93)$ \\
Constant & -0.00 & -0.00 & 0.00 & 0.00 & 0.00 & $6.96^{* * *}$ & $441.82^{* * *}$ \\
& $(0.02)$ & $(0.02)$ & $(0.02)$ & $(0.02)$ & $(0.02)$ & $(0.09)$ & $(38.37)$ \\
\hline Observations & 1014 & 1014 & 1014 & 1014 & 1014 & 1014 & 1014 \\
\hline
\end{tabular}

OLS model with robust standard errors. ${ }^{+} p<0.10,{ }^{*} p<0.05,{ }^{* *} p<0.01,{ }^{* * *} p<0.001$

Table 3: Regressions of CSO sub-characteristics related to technical capacity and the social costs of sanctions on women's decision-making power index

\begin{tabular}{lcccccc}
\hline & Polit. Know. & Comm. Influ. & Int. Coord. & Fin. Vuln. & Dep. Mayor & Dep. Comm. \\
\hline Women's decision-making index & $0.04^{*}$ & 0.01 & $0.05^{*}$ & $-0.12^{* * *}$ & $0.14^{* * *}$ & 0.03 \\
& $(0.02)$ & $(0.03)$ & $(0.02)$ & $(0.02)$ & $(0.03)$ & $(0.02)$ \\
Constant & 0.00 & -0.00 & -0.00 & 0.00 & 0.00 & 0.00 \\
& $(0.02)$ & $(0.02)$ & $(0.02)$ & $(0.02)$ & $(0.03)$ & $(0.02)$ \\
\hline Observations & 1014 & 1014 & 1014 & 1014 & 1014 & 1014 \\
\hline
\end{tabular}

OLS model with robust standard errors. ${ }^{+} p<0.10,{ }^{*} p<0.05,{ }^{* *} p<0.01,{ }^{* * *} p<0.001$

Table 4 and Table 5 then consider - for our main indices and two sanctioning outcomes, and for our sub-indices, respectively_-whether the relationship between women's decision-making in the home and these outcomes varies with the gender of the respondent. We do not find robust evidence 
that this is the case; an interaction term between our women's decision-making index and respondent gender is in all cases statistically insignificant at conventional levels. Nonetheless, it is notable that for the outcome transfer size from the mayor (i.e., the amount the CSO leader anticipates receiving from the mayor in exchange for remaining silent in the face of known corruption), the magnitude of the effect size for women is less than half that for men. If anything this would suggest that for men, but less so for women, having a household in which women make more decisions predicts greater ability to extract transfers from the mayor. However, barring statistically significant differences across gender, we are hesitant to make any strong conclusions.

Table 4: Regressions of CSO characteristics and sanction-related outcomes on women's decisionmaking power index and its interaction with gender

\begin{tabular}{|c|c|c|c|c|c|c|c|}
\hline & Hierarchy & Embed. & Info. Cap. & Tech. Cap. & Soc. Costs & Sanction & Trans. Size \\
\hline \multirow[t]{2}{*}{ Women's decision-making index } & 0.04 & 0.01 & -0.01 & 0.04 & -0.01 & 0.05 & 83.17 \\
\hline & $(0.03)$ & $(0.03)$ & $(0.03)$ & $(0.03)$ & $(0.03)$ & $(0.15)$ & $(76.04)$ \\
\hline \multirow[t]{2}{*}{ Male } & -0.02 & $0.09^{*}$ & $0.21^{* * *}$ & $0.16^{* * *}$ & $-0.07^{*}$ & $0.52^{* *}$ & 5.62 \\
\hline & $(0.03)$ & $(0.04)$ & $(0.03)$ & $(0.03)$ & $(0.03)$ & $(0.18)$ & $(79.28)$ \\
\hline \multirow[t]{2}{*}{ Male $\times$ WDI } & -0.00 & 0.03 & -0.00 & -0.01 & -0.02 & -0.19 & 117.07 \\
\hline & $(0.04)$ & $(0.04)$ & $(0.04)$ & $(0.03)$ & $(0.03)$ & $(0.19)$ & $(95.03)$ \\
\hline \multirow[t]{2}{*}{ Constant } & 0.01 & $-0.05^{+}$ & $-0.13^{* * *}$ & $-0.10^{* * *}$ & 0.04 & $6.64^{* * *}$ & $447.09^{* * *}$ \\
\hline & $(0.03)$ & $(0.03)$ & $(0.03)$ & $(0.02)$ & $(0.03)$ & $(0.14)$ & $(60.52)$ \\
\hline Observations & 991 & 991 & 991 & 991 & 991 & 991 & 991 \\
\hline
\end{tabular}

Table 5: Regressions of CSO sub-characteristics related to technical capacity and the social costs of sanctions on women's decision-making power index and its interaction with gender

\begin{tabular}{lcccccc}
\hline & Polit. Know. & Comm. Influ. & Int. Coord. & Fin. Vuln. & Dep. Mayor & Dep. Comm. \\
\hline Women's decision-making index & $0.07^{*}$ & -0.02 & 0.06 & $-0.10^{*}$ & $0.10^{*}$ & 0.06 \\
& $(0.03)$ & $(0.04)$ & $(0.03)$ & $(0.04)$ & $(0.05)$ & $(0.04)$ \\
Male & $0.36^{* * *}$ & $0.13^{* *}$ & 0.03 & $-0.24^{* * *}$ & 0.03 & $0.15^{* *}$ \\
& $(0.04)$ & $(0.05)$ & $(0.04)$ & $(0.05)$ & $(0.06)$ & $(0.05)$ \\
Male $\times$ WDI & -0.03 & 0.04 & -0.01 & -0.02 & 0.07 & -0.05 \\
& $(0.04)$ & $(0.05)$ & $(0.04)$ & $(0.05)$ & $(0.06)$ & $(0.05)$ \\
Constant & $-0.22^{* * *}$ & $-0.08^{*}$ & -0.02 & $0.14^{* * *}$ & -0.02 & $-0.09^{*}$ \\
& $(0.03)$ & $(0.04)$ & $(0.03)$ & $(0.04)$ & $(0.05)$ & $(0.04)$ \\
\hline Observations & 991 & 991 & 991 & 991 & 991 & 991 \\
\hline
\end{tabular}

OLS model with robust standard errors. ${ }^{+} p<0.10,{ }^{*} p<0.05,{ }^{* *} p<0.01,{ }^{* * *} p<0.001$ 


\subsubsection{CSO characteristics and sanctioning outcomes by gender}

We next examine how well our indices measuring CSO characteristics defined above and their interactions with gender predict our two sanctioning-related outcomes: willingness to sanction and expected transfer price. In Table 6 we utilize an indicator for the respondent being male, while in Table 7, we utilize an indicator for the leader's CSO having 25 percent or more men among its members (i.e., an indicator for not being woman-dominated). For each outcome variable, we present two models. In the first, we include the five main indices, while in the second, we disaggregate Technical capacity and Social cost of sanctioning into their component sub-indices.

One of the most striking findings is the fact that being a hierarchical organization, for women respondents as well as for women-dominated CSOs, predicts a significantly lower willingness to sanction and a significantly smaller expected transfer size from the mayor for staying quiet, whereas for men we see virtually no relationship between the hierarchy index and the two sanctioning outcomes. For both genders of respondents, and for both women's groups and other CSOs, we also find that greater technical capacity increases willingness to sanction, while greater embeddedness increases the expected transfer from the mayor.

Turning to sub-indices (Table 6, columns 2 and 4), it is striking that for women respondents, political knowledge predicts greater willingness to sanction and a lower expected transfer from the mayor, whereas for men there is a similar (positive) relationship with willingness to sanction, but no relationship with expected transfer. Women, but not men, are harmed by political knowledge in terms of how large of a transfer they can anticipate from the mayor. Results are similar in Table 7 (column 4) when comparing women's CSOs with others. We also find that for women, mobilization capacity predicts a larger transfer from the mayor, but this relationship is absent among male respondents. Similar though less statistically significant results hold when comparing women's CSOs with others. 
Table 6: Regressions of sanction-related outcomes on CSO characteristics and their interactions with the gender of the respondent

\begin{tabular}{|c|c|c|c|c|}
\hline & \multicolumn{2}{|c|}{ Willingness to sanction } & \multicolumn{2}{|c|}{ Expected transfer } \\
\hline & Main indices & Sub-indices & Main indices & Sub-indices \\
\hline \multirow[t]{2}{*}{ Male } & 0.16 & 0.12 & -21.12 & 24.61 \\
\hline & $(0.17)$ & $(0.17)$ & $(83.59)$ & $(79.28)$ \\
\hline \multirow[t]{2}{*}{ Hierarchy Index } & $-1.44^{* * *}$ & $-1.37^{* * *}$ & $-386.27^{* * *}$ & $-326.56^{* *}$ \\
\hline & $(0.26)$ & $(0.26)$ & $(114.55)$ & $(107.05)$ \\
\hline \multirow[t]{2}{*}{ Embeddedness Index } & -0.06 & -0.44 & $228.06^{*}$ & $225.50^{+}$ \\
\hline & $(0.26)$ & $(0.28)$ & $(109.26)$ & $(115.68)$ \\
\hline \multirow[t]{2}{*}{ Informational Capacity Index } & 0.34 & $0.45^{+}$ & 127.05 & 97.92 \\
\hline & $(0.26)$ & $(0.24)$ & $(154.35)$ & $(151.64)$ \\
\hline \multirow[t]{2}{*}{ Technical Capacity Index } & $1.49^{* * *}$ & & 17.43 & \\
\hline & $(0.32)$ & & $(126.49)$ & \\
\hline \multirow[t]{2}{*}{ Social Cost of Sanctioning Index } & -0.35 & & 223.89 & \\
\hline & $(0.22)$ & & $(150.21)$ & \\
\hline \multirow[t]{2}{*}{ Male $\times$ Hierarchy Index } & $0.94^{* *}$ & $0.93^{* *}$ & $497.42^{* *}$ & $426.39^{* *}$ \\
\hline & $(0.33)$ & $(0.33)$ & $(153.14)$ & $(144.54)$ \\
\hline \multirow[t]{2}{*}{ Male $\times$ Embeddedness Index } & -0.12 & 0.04 & -10.94 & -51.35 \\
\hline & $(0.32)$ & $(0.34)$ & $(142.14)$ & $(149.59)$ \\
\hline \multirow[t]{2}{*}{ Male $\times$ Informational Capacity Index } & 0.41 & 0.43 & -128.42 & -107.39 \\
\hline & $(0.35)$ & $(0.33)$ & $(192.61)$ & $(192.65)$ \\
\hline \multirow[t]{2}{*}{ Male $\times$ Technical Capacity Index } & 0.09 & & -1.44 & \\
\hline & $(0.44)$ & & $(190.95)$ & \\
\hline \multirow[t]{2}{*}{ Male $\times$ Social Cost of Sanctioning Index } & 0.41 & & -115.67 & \\
\hline & $(0.31)$ & & $(176.85)$ & \\
\hline \multirow[t]{2}{*}{ Political Knowledge Sub-Index } & & $0.52^{*}$ & & $-316.19^{* * *}$ \\
\hline & & $(0.23)$ & & $(92.68)$ \\
\hline \multirow[t]{2}{*}{ Community Influence Sub-Index } & & $1.22^{* * *}$ & & 48.75 \\
\hline & & $(0.22)$ & & $(109.60)$ \\
\hline \multirow[t]{2}{*}{ Mobilization Capacity Sub-index } & & -0.09 & & $193.99^{+}$ \\
\hline & & $(0.27)$ & & $(116.42)$ \\
\hline \multirow[t]{2}{*}{ Financial Vulnerability Sub-index } & & 0.13 & & 41.18 \\
\hline & & $(0.17)$ & & $(109.56)$ \\
\hline \multirow[t]{2}{*}{ Mayor Dependence Sub-index } & & $-0.29^{+}$ & & 51.22 \\
\hline & & $(0.15)$ & & $(67.87)$ \\
\hline \multirow{2}{*}{ Community Dependence Sub-index } & & -0.06 & & 100.71 \\
\hline & & $(0.19)$ & & $(67.24)$ \\
\hline \multirow[t]{2}{*}{ Male $\times$ Political Knowledge Sub-Index } & & 0.11 & & $327.03^{*}$ \\
\hline & & $(0.33)$ & & $(151.52)$ \\
\hline \multirow[t]{2}{*}{ Male $\times$ Community Influence Sub-Index } & & $-0.49^{+}$ & & -19.09 \\
\hline & & $(0.29)$ & & $(143.22)$ \\
\hline Male $\times$ Mobilization Capacity Sub-index & & 0.49 & & $-299.84^{+}$ \\
\hline & & $(0.35)$ & & $(160.41)$ \\
\hline Male $\times$ Financial Vulnerability Sub-index & & 0.02 & & -26.58 \\
\hline & & $(0.22)$ & & $(133.78)$ \\
\hline Male $\times$ Mayor Dependence Sub-index & & -0.09 & & -101.88 \\
\hline & & $(0.18)$ & & $(91.51)$ \\
\hline Male $\times$ Community Dependence Sub-index & & 0.26 & & 58.82 \\
\hline & & $(0.24)$ & & $(98.36)$ \\
\hline Constant & $6.85^{* * *}$ & $6.86^{* * *}$ & $470.47^{* * *}$ & $415.70^{* * *}$ \\
\hline & $(0.13)$ & $(0.12)$ & $(65.94)$ & $(61.55)$ \\
\hline Observations & 991 & 991 & 991 & 991 \\
\hline
\end{tabular}


Table 7: Regressions of sanction-related outcomes on CSO characteristics and their interactions with the gender of the CSO

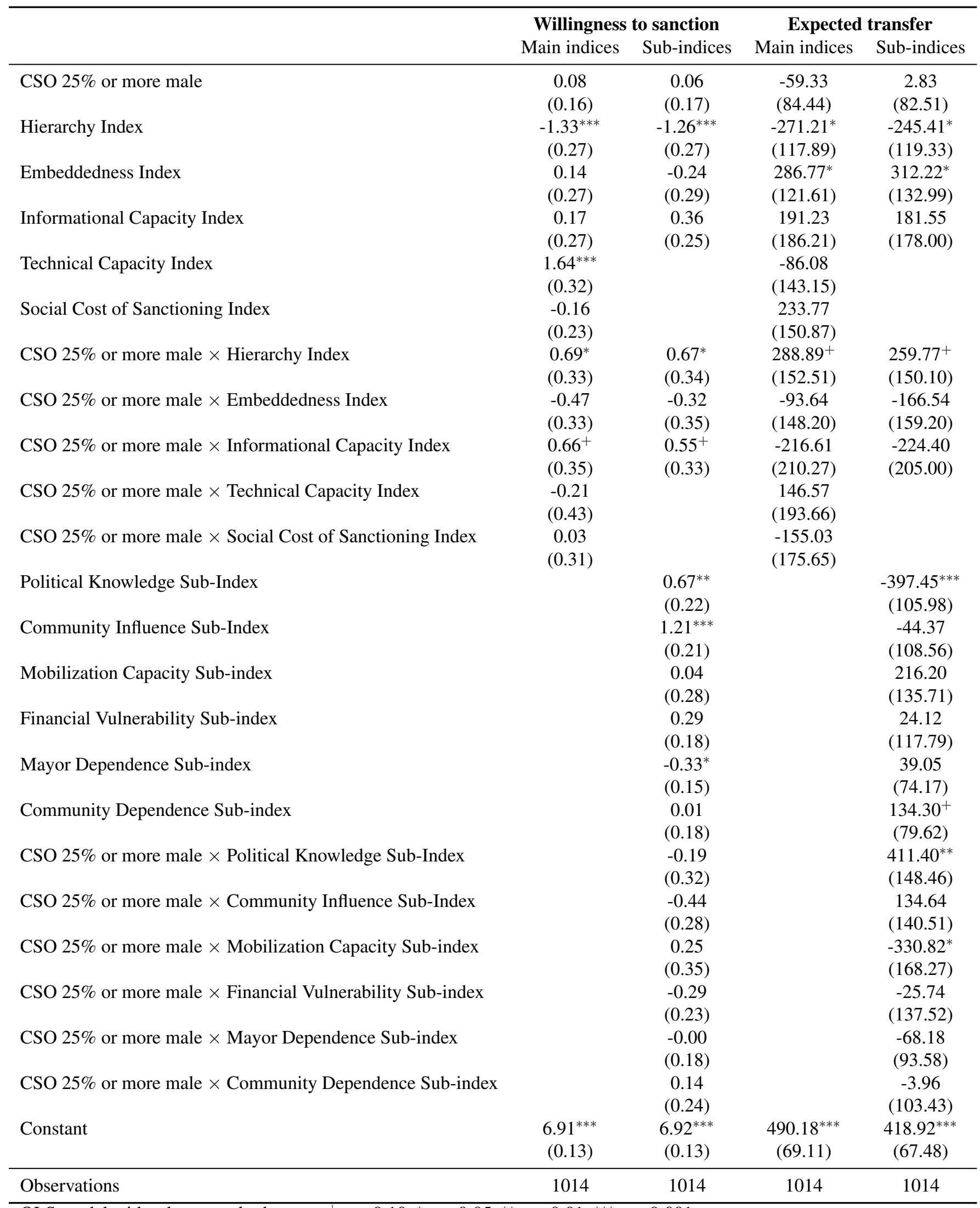

OLS model with robust standard errors. ${ }^{+} p<0.10,{ }^{*} p<0.05,{ }^{* *} p<0.01,{ }^{* * *} p<0.001$ 


\subsubsection{Experimental treatments and sanctioning outcomes by gender}

Finally, we consider how our experimental treatments impact our sanctioning-related outcomes, by gender of the respondent and gender of the CSO. The most striking finding is that our experimental treatment 1 (T1) - priming the CSO leader to feel that their CSO is important—results in a significantly lower likelihood of sanctioning for women, though not for men (Table 8, column 1). This difference between genders is furthermore itself statistically significant. When women respondents are told that the CSO they lead is important and selected for interview on this basis, they become much less willing to report that they will sanction. We find similarly statistically significant impacts of T1 when we use our CSO-level measure of gender (column 2); women's CSOs, but not other types, become significantly less likely to sanction when importance is primed.

We find a statistically significant difference between genders for the duration treatment, which induces variation in the expected duration the CSO would serve as monitor. Here (Table 8, column 3) we see that women who know they will have the role of monitor of the mayor for only on year are significantly less likely than are men to react to that information with increased sanctioning behavior. Women do not respond to the treatment, while men experience a positive impact in sanctioning behavior that is statically significantly greater than the coefficient for women. The duration treatment, however, has no effect on expected transfer size from the mayor for either gender. Further, the findings for sanctioning behavior do not hold when we define gender in terms of the CSO's membership as opposed to the respondents gender (column 4).

\section{Conclusion}

Our data suggest that lack of social capital or organizing capacity are not likely to be binding constraints on women's civic participation in Mali. Indeed, such efforts often fail to close the gender gap in civic participation, and can even exacerbate it (Gottlieb, 2016b; Beath, Christia and Enikolopov, 2013; Mabsout and Van Staveren, 2010; Cornwall, 2003). Instead, the biggest constraint appears to be translating women's group participation, and the organizing capacity that 
Table 8: Regressions of willingness to sanction on randomized treatments related to sanctioning environment and their interactions with gender (of respondent and CSO)

\begin{tabular}{|c|c|c|c|c|c|c|}
\hline & \multicolumn{2}{|c|}{ Importance treatment } & \multicolumn{2}{|c|}{ Duration treatment } & \multicolumn{2}{|c|}{ Annonymity treatment } \\
\hline & Respondent & CSO & Respondent & $\mathrm{CSO}$ & Respondent & $\mathrm{CSO}$ \\
\hline Male & $\begin{array}{c}0.19 \\
(0.25)\end{array}$ & & $\begin{array}{c}0.21 \\
(0.26)\end{array}$ & & $\begin{array}{c}0.38 \\
(0.24)\end{array}$ & \\
\hline CSO $25 \%$ or more male & & $\begin{array}{l}-0.10 \\
(0.24)\end{array}$ & & $\begin{array}{l}0.48^{+} \\
(0.26)\end{array}$ & & $\begin{array}{l}0.59^{*} \\
(0.24)\end{array}$ \\
\hline Importance Treatment & $\begin{array}{c}-0.45^{+} \\
(0.27)\end{array}$ & $\begin{array}{c}-0.87^{* *} \\
(0.28)\end{array}$ & & & & \\
\hline Duration Treatment & & & $\begin{array}{l}-0.32 \\
(0.27)\end{array}$ & $\begin{array}{c}0.06 \\
(0.28)\end{array}$ & & \\
\hline Anonymity Treatment & & & & & $\begin{array}{l}-0.15 \\
(0.27)\end{array}$ & $\begin{array}{c}0.08 \\
(0.28)\end{array}$ \\
\hline Male $\times$ Importance Treatment & $\begin{array}{l}0.65^{+} \\
(0.35)\end{array}$ & & & & & \\
\hline CSO $25 \%$ or more male $\times$ Importance & & $\begin{array}{c}1.20^{* * *} \\
(0.35)\end{array}$ & & & & \\
\hline Male $\times$ Duration Treatment & & & $\begin{array}{l}0.64^{+} \\
(0.35)\end{array}$ & & & \\
\hline CSO $25 \%$ or more male $\times$ Duration & & & & $\begin{array}{c}0.08 \\
(0.36)\end{array}$ & & \\
\hline Male $\times$ Anonymity Treatment & & & & & $\begin{array}{c}0.28 \\
(0.35)\end{array}$ & \\
\hline CSO $25 \%$ or more male $\times$ Annonymity & & & & & & $\begin{array}{l}-0.13 \\
(0.36)\end{array}$ \\
\hline Constant & $\begin{array}{c}6.88^{* * *} \\
(0.19)\end{array}$ & $\begin{array}{c}7.08^{* * *} \\
(0.18)\end{array}$ & $\begin{array}{c}6.79^{* * *} \\
(0.19)\end{array}$ & $\begin{array}{c}6.59^{* * *} \\
(0.20)\end{array}$ & $\begin{array}{c}6.72^{* * *} \\
(0.19)\end{array}$ & $\begin{array}{c}6.59^{* * *} \\
(0.19)\end{array}$ \\
\hline Observations & 991 & 1014 & 991 & 1014 & 991 & 1014 \\
\hline
\end{tabular}

OLS model with robust standard errors. ${ }^{+} p<0.10,{ }^{*} p<0.05,{ }^{* *} p<0.01,{ }^{* * *} p<0.001$ 
underlies it, into effective civic and political engagement.

Lessons in existing literature can inform this challenge of translating organizing capacity into civic and political engagement. For example, Ndlovu and Mutale (2013) cite factors that have led to increased women's political participation in Africa, such as the proliferation of women's movement groups, educational opportunities, economic empowerment, and civil society advocacy. Relatedly, Bleck and Michelitch (2018) find that greater socioeconomic empowerment, measured as mobility outside the village and participation in household decision-making, is correlated with greater political knowledge, political opinions, and support for pro-women policies among rural women. Chawla et al. (2017) agree that investing in women's movements is key: they find that encouraging women's diverse organizing and mobilization leads to more successful civic and political participation. Investments in women's movements should also take into account existing findings on the structural features of organizations that make them more successful, such as the existence of a board, whether decisions are made by general assembly, or having a system of accountability (Wouterse, Faye et al., 2020).

More research is needed about which strategies for converting women's organizational capacity into civic and political engagement will work best-and with which groups and environments. For example, one can imagine that the challenges are distinct within formal compared to informal groups (which may face distinct challenges in interfacing with and challenging the state). They may also be distinct for groups focused on community development versus education, for example. Case studies of particularly successful women-led CSOs would be especially useful in revealing what factors give those groups agency and voice. Finally, more work is needed, broadly, on drivers of women's collective agency — and to develop rigorous methods and tools for measuring that collective agency. 


\section{References}

Adams, Alayne M, Sangeetha Madhavan and Dominique Simon. 2002. "Women's social networks and child survival in Mali." Social science \& medicine 54(2):165-178.

Beath, Andrew, Fotini Christia and Ruben Enikolopov. 2013. "Empowering women through development aid: Evidence from a field experiment in Afghanistan." American Political Science Review 107(3):540-557.

Bleck, Jaimie. 2015. Education and empowered citizenship in Mali. JHU Press.

Bleck, Jaimie and Kristin Michelitch. 2018. "Is women's empowerment associated with political knowledge and opinions? Evidence from rural Mali." World Development 106:299-323.

Chattopadhyay, Raghabendra and Esther Duflo. 2004. "Women as policy makers: Evidence from a randomized policy experiment in India." Econometrica 72(5):1409-1443.

Clayton, Amanda, Amanda Lea Robinson, Martha C Johnson and Ragnhild Muriaas. 2020. "(How) do voters discriminate against women candidates? Experimental and qualitative evidence from Malawi." Comparative Political Studies 53(3-4):601-630.

Cornwall, Andrea. 2003. "Whose voices? Whose choices? Reflections on gender and participatory development." World development 31(8):1325-1342.

De Jorio, Rosa. 1997. Female elites, women's formal associations, and political practices in urban Mali (West Africa). University of Illinois at Urbana-Champaign.

Duncan, Lauren E. 2012. “The psychology of collective action.”.

Ekeh, Peter P. 1975. "Colonialism and the two publics in Africa: A theoretical statement." Comparative studies in society and history 17(1):91-112.

Gottlieb, Jessica. 2015. “The logic of party collusion in a democracy: Evidence from Mali." World Politics 67(1):1-36.

Gottlieb, Jessica. 2016a. "Greater expectations: A field experiment to improve accountability in Mali." American Journal of Political Science 60(1):143-157.

Gottlieb, Jessica. 2016b. "Greater Expectations: A Field Experiment to Improve Accountability in Mali." American Journal of Political Science 60(01):143-157.

Gottlieb, Jessica and Katrina Kosec. 2019. "The countervailing effects of competition on public goods provision: When bargaining inefficiencies lead to bad outcomes." American Political Science Review 113(1):88-107.

Hägi, Mathieu, Jean-François Schémann, Frédéric Mauny, Germain Momo, Doulaye Sacko, Lamine Traoré, Denis Malvy and Jean-François Viel. 2010. "Active trachoma among children in Mali: Clustering and environmental risk factors." PLoS neglected tropical diseases 4(1):e583. 
Hern, Erin. 2019. Developing states, shaping citizenship: Service delivery and political participation in Zambia. University of Michigan Press.

Humphreys, Macartan, William A Masters and Martin E Sandbu. 2006. "The role of leaders in democratic deliberations: results from a field experiment in São Tomé and Príncipe." World Politics 58(4):583-622.

Jack, B Kelsey and María P Recalde. 2015. "Leadership and the voluntary provision of public goods: Field evidence from Bolivia." Journal of Public Economics 122:80-93.

Johnson, Cathryn Evangeline. 2021. "Connecting Malian and Burkinabe women's local experiences of livelihood security to how they participate in politics." World Development 137:105157.

Kang, Alice J. 2015. Bargaining for Women's Rights: activism in an aspiring Muslim democracy. U of Minnesota Press.

Kasfir, Nelson. 2013. Civil Society and Democracy in Africa: critical perspectives. Routledge.

Khemani, Stuti, Ernesto Dal Bó, Claudio Ferraz, Frederico Finan, Corinne Stephenson, Sina Odugbemi, Dikshya Thapa and Scott Abrahams. 2016. "Making Politics Work for Development: A Policy Research Report.".

Krook, Mona Lena. 2017. "Violence against women in politics.” Journal of Democracy 28(1):74-88.

Lasater, Molly E, Sarah M Murray, Mariam Keita, Fatoumata Souko, Pamela J Surkan, Nicole E Warren, Peter J Winch, Aissata Ba, Seydou Doumbia and Judith K Bass. 2021. "Integrating Mental Health into Maternal Health Care in Rural Mali: A Qualitative Study." Journal of Midwifery \& Women's Health 66(2):233-239.

Lindberg, Staffan I. 2010. "What accountability pressures do MPs in Africa face and how do they respond? Evidence from Ghana." The Journal of Modern African Studies 48(1):117-142.

Logan, Carolyn and Michael Bratton. 2006. “The political gender gap in africa: Similar attitudes, different behaviors.".

Mabsout, Ramzi and Irene Van Staveren. 2010. "Disentangling bargaining power from individual and household level to institutions: Evidence on women's position in Ethiopia." World Development 38(5):783-796.

Medie, Peace A. 2013. "Fighting gender-based violence: The women's movement and the enforcement of rape law in Liberia." African Affairs 112(448):377-397.

Meier zu Selhausen, Felix. 2016. "What determines women's participation in collective action? Evidence from a western Ugandan coffee cooperative.” Feminist Economics 22(1):130-157.

Ndlovu, Sibonokuhle and Sani Boniface Mutale. 2013. "Emerging trends in women's participation in politics in Africa." American International Journal of Contemporary Research 3(11):72-79. 
Roy, Shalini, Melissa Hidrobo, John Hoddinott and Akhter Ahmed. 2019. "Transfers, behavior change communication, and intimate partner violence: Postprogram evidence from rural Bangladesh." Review of Economics and Statistics 101(5):865-877.

Schulz, Dorothea. 2003. "Political factions, ideological fictions: The controversy over family law reform in democratic Mali." Islamic Law and Society 10(1):132-164.

Tripp, Aili Mari. 2000. Women and politics in Uganda. Univ of Wisconsin Press.

Tripp, Aili Mari. 2004. "Women's movements, customary law, and land rights in Africa: The case of Uganda." African Studies Quarterly 7(4):1-19.

Tripp, Aili Mari and Alice Kang. 2008. "The global impact of quotas: On the fast track to increased female legislative representation.” Comparative Political Studies 41(3):338-361.

Wing, Susanna D. 2012. "Human rights-based approaches to development: Justice and legal fiction in Africa." Polity 44(4):504-522.

Wing, Susanna D. 2013. "Mali: Politics of a crisis.” African Affairs 112(448):476-485.

Wouterse, Fleur Stephanie, Amy Faye et al. 2020. "Institutions of collective action and smallholder performance: Evidence from Senegal." 2020 Annual Trends and Outlook Report: Sustaining Africa's Agrifood System Transformation: The Role of Public Policies pp. 87-101. 


\section{Appendix}

Women's Voices in Civil Society Organizations: Evidence froma Civil Society Mapping Project in Mali

Jaimie Bleck, Jessica Gottlieb, and Katrina Kosec 


\section{A Sample Selection}

\section{Appendix A Mapping Exercise}

The process by which enumerators selected respondents for the mapping exercise varied slightly across rural vs. urban areas. For rural areas, we sent enumerators to the chef-lieu (the administrative seat of the cercle that houses cercle-level administration, and typically the largest municipality) of each cercle in our sample and asked them to identify eight people from the commune of interest. These eight interlocutors should live in the chief-lieu but hail originally from one of the two strongest villages in the commune (typically, the commune seat and another economic center). They would then interview four respondents from each of these two villages. For urban areas, we had enumerators divide the city into 4 geographic parts and select four people from each neighborhood. For each village (for rural areas) or neighborhood (for urban areas), enumerators were asked to identify four respondents from different sectors of society. They did so with large discretion, but were asked to include at least one woman and at least one youth. Further, if the village (neighborhood) was characterized by a significant cleavage (e.g., ethnic or religious), they were asked to select one respondent from each side of the cleavage. Finally, respondents must have visited the village (neighborhood) at least two times in the last six months.

\section{Appendix B Survey}

Within each of the 48 rural and urban communes maintained from the mapping exercise, we used block randomization to select 20 or 24 CSOs in each, respectively. ${ }^{11}$ We blocked on CSO gender composition (all male, all female, or mixed) and CSO formality (formal or informal), creating six group types; we then selected at least four CSOs in the commune from each particular group type. The resulting sample thus expresses substantial variation within each commune on two of our dimensions of interest - gender composition and formality. ${ }^{12}$ This resulted in exactly one of

\footnotetext{
${ }^{11}$ With the exception of three of the smaller 30 rural communes for which we selected only 16 CSOs.

${ }^{12}$ See Appendix A for further details.
} 
each of the six group types in urban communes $(6 \times 4=24)$ and five of the six group types in rural communes $(5 \times 4=20) .{ }^{13}$ This yielded a sample size of $18 \times 24=432$ CSOs from urban communes and $27 \times 20+3 \times 16=588$ CSOs from rural communes, for a total of 1,020 CSOs. We instructed the survey firm to replace CSO leaders that could not be interviewed with another CSO from the same commune (and also from the same block within the commune, where possible)—flagging those CSO leaders that are replacements.

\section{B Random Assignment of Treatment and Power Calculations}

Assignment to the four vignette conditions (combinations of T2 and T3) is first stratified on commune and then on CSO type. We expect that the particularities of political competition and local governance will vary considerably by commune and overall affect willingness to sanction. We therefore aim to increase precision of our estimated treatment effects by stratifying on commune, the level at which local governments operate.

We additionally expect characteristics of the CSO to moderate willingness to sanction, but have only limited baseline characteristics of these CSOs from the mapping exercise. We therefore use a combination of two characteristics: formality (formal vs. informal) and gender composition (women only, men only, and mixed) to create six distinct group types. Within each commune, we then stratify assignment of the four vignette types by CSO type.

To avoid interaction effects between T1 and the vignette treatments (T2 and T3), we assigned T1 - the group importance prime - at the group type level (defined by the group's gender composition and whether it is formal). To ensure balance, we stratify the assignment of T1 to blocks at the commune level.

Our sample of unique mapped CSOs $(2,666)$ is larger than the number of CSOs necessary to

\footnotetext{
${ }^{13}$ This procedure worked with some minor adjustments. In urban areas, some communes had fewer than four CSOs of a given group type; in that case, we created a second group of the most populous group type. For example, if the urban commune had a lot of mixed formal groups, then we created two groups (of four CSOs each) of that type to compensate for the missing group type. In rural areas, some communes were missing one or more group types, so we repeated the above procedure. Then, some rural communes had all six group types; because we could not survey 24 CSOs, we dropped the least common group type and left the remaining five.
} 
achieve the desired power of our hypothesis tests. Focusing on T2 and T3, to detect a minimum detectable effect size of 0.25 standard deviations with $80 \%$ power and $95 \%$ statistical significance, we require about 252 units in each of the four treatment groups, making our chosen sample sizes of 255 CSOs each adequate to detect these effect sizes.

\section{Survey Questions}

\section{Group characteristics}

- Q1. Is the majority of the members of your group from the same village?

- Q2. Where does your group operate now? (could relate to embeddedness ( $\theta$ or $j$ ) or capacity (n)

- Same village/neighborhood

- Same town

- Same circle

- Same region

- North of the country

- Center of the country

- South of the country

- National level

- Q3. What is the age of the oldest member and the youngest member? How old is the typical member?

- Q3A. Age of the oldest member

- Q3B. Age of the youngest member

- Q3C. If you were describing a typical member of your group, what age would you say they had?

- Q4. What proportion of your group is feminine?

- Q5. In what genre of activities is your organization engaged? 
- Q5AA1. Advocacy

- Q5AA2.Civic engagement

- Q5AA3. Awareness raising/ Information dissemination

- Q5AA4. Agriculture/ Market gardening

- Q5AA5. Trade

- Q5AA6. Manufacturing/Processing

- Q5AA7. Microfinance

- Q5AA8. Savings group

- Q5AA9. Skilled labor

- Q5AA10. Skills/Vocational training

- Q5AA11. Education

- Q5AA12. Financing of public goods/ Social protection/ Community development

- Q5AA13. Environmental conservation/ Reforestation

- Q5AA14. Healthcare

- Q5AA15. Legal assistance

- Q5AA16. Peace/ conflict resolution

- Q5AA17. Road maintenance

- Q5AA18. Security

- Q5AA19. Faith based activities/Religious activities

- Q5AA20. Sanitation

- Q5AA21. Socialization

- Q5AA22. Sports/Games/Leisure

- Q5AA23. Promotion of femmes

- Q5AA24. Other. Specify other.

- Q5A. Among these activities, which would you consider your primary activity?

- Trade

- Microfinance 
- Specify other

\section{H??: Egalitarian versus hierarchical structure $(h)$}

- Q6. How many leaders does your group have in this town?

- Q6A. Among these leaders, how many are women?

- Q7. Is there a person or are there people who can prevent your group from taking action? Would you say that it's the leader only, the leader only if supported by a few members, the leader only if supported by a majority of members, or leader only if supported by all members who can prevent your group from taking action?

- The leader only

- The leader only if supported by some members

- The leader only if supported by the majority of members

- The leader only if supported by all members

- Q8. If someone wants to withdraw money from the group savings account or other inputs in which the group is storing, who should authorize it?

- The leader only

- The treasurer only

- The leader or treasurer (one is enough)

- The leader and the treasurer (both are necessary)

- Does not have a savings account

- Q9. What is the meeting place of your group if there is one?

- The house of the leader

- The public meeting place of the village

- Rotation among members

- None

- At what frequency do members of your groups meet?

$-1=$ Several times per week 
-2 = Bi-weekly

$-3=$ Weekly

- 4 = Every two weeks

- 5 = Monthly

- 6 = Quarterly

$-7=$ Twice per year

- $8=$ Once per year

- Q11. Which languages do the members of your group typically speak when they are together for reunions?

- Bamanakan

- Songhai

- Peul

- Dogon

- Bozo

- Tamashek

- Khassonke

- Senufo

- Mianka

- Sarakole

- Bomu

- French

- Q12. Is it the same maternal language as the leader of your group?

- Yes

- No

- Q13. Which is the part of your members of your organization who have a big influence on the decision making on what your group does and the direction that your group must take? Please tell me on a scale of 1 to 10 (1 indicating that the leader is the only one 
to make decisions and 10 indicating that all the members participate equally in all the decision making), what is the rate that you would give on the decision making within your organization. Rating of 1 to 10

- Q14. To what extent do you think that an individual member would succeed at influencing the leader(s) of this organization if the leader did not yet agree with the member? Would you say that it's...

- 1 = Certainly possible

- 2 = Potentially possible

$-3=$ Could be possible or impossible

- 4 = Almost impossible

- 5 = Certainly impossible

\section{H??: The value of credibility or reputation $(g)$}

- Q15. How often do the members of your group interact with non-member citizens to share priorities or interact regarding other subjects?

$-1=$ Several times per week

-2 = Biweekly

- 3 = Every two weeks

- 4 = Monthly

-5 = Quarterly

$-6=$ Twice per year

$-7=$ Once per year

- Q16. When was your group founded?

- Q17. How would you characterize your group's objectives? Do you think that you have long-term objectives? Like something that you want to achieve in at least a year, while short-term objectives are things that you want to achieve now or in the next few months.

$-1=$ Objectives are always long-term 
$-2=$ Objectives are often long-term

- 3 = A mix of long and short term objectives

- 4 = Objectives are most often short-term

$-5=$ Objectives are always short-term

- Q18. How many members (simple members) does your group have in this town excluding the leaders?

- Q19. To what extent do the citizens of your community with whom you interact regularly know the activities, objectives, and actions of your group?

- 1 = The majority of the people with whom I interact know my group

$-2=$ A lot of the people with whom I interact know my group

$-3=$ Some people with whom I interact know my group

- 4 = Almost none of the people with whom I interact know my group

- Q20. To what extent do the citizens of your community know the actions and performances of the mayor?

$-1=$ The majority of people with whom I interact know the actions and performances of the mayor

$-2=$ A lot of people with whom I interact know the actions and performances of the mayor

- $3=$ Some people with whom I interact know the actions and performances of the mayor

- 4 = Almost none of the people with whom I interact know the actions and performances of the mayor

\section{H??: The expectation of future favoritism $(\theta)$}

- Q21. Do you know the name of the mayor of your town?

- Yes, they give correct name 
- Yes, they pretend to know but don't remember the name

- No

- Q22A. Do you have the telephone number of the mayor in your cell phone?

- Q22B. If not, do you have the telephone number of another member of the town council?

- Q22C. If yes, is this person a member of the mayor's party or the opposition?

$-1=$ Coalition

- 2 = Opposition

- Q22D. Do you know from which family the mayor comes?

- $1=$ Yes, they give basic details of the family biography

$-2=$ No, they cannot supply basic details on family biography

- 3 = Don't know

- Q23. Do you know how many seats are on the town council?

- 1 = Yes, correct

$-2=$ No, incorrect

- 3 = Don't know

- Q24. In the last two years, have you received funding or materials from the local government?

- Yes

- No

- Q25. In the last two years, have you received any funding or materials from a donor or NGO?

- Yes

- No

- Q25A. . In the last two years, have you held a meeting with a donor or NGO for your CSO account?

- Yes

- No 
- Q26. How often do the members of your group interact with the elected leaders in your town?

$-1=$ Several times per week

-2 = Biweekly

$-3=$ Weekly

- 4 = Every two weeks

- 5 = Monthly

$-6=$ Quarterly

$-7=$ Twice per year

$-8=$ Once per year

Q27.

- If your group would like to contact or solicit a local government community member to advocate for your group, do you have someone you can contact?

- yes

- no

- Q28. If yes, who would you contact?

- Q29. Do you share one of the following connections with this person?

- Ethnicity

- Caste

- Family

- Work/School

- Q30. What is that person's profession?

- Traditional leader

- Religious leader

- An entrepreneur/rich person

- A soldier/policeman/official

- Other. Specify 
- Q31. If the mayor were to use part of the public budget to support his friends and family, what's the probability on a scale of 0 to 10 that you would know about it ( 0 indicating that you certainly would not know and 10 indicating that you would surely know). Scale of 0 to $10(10=$ you would surely know $)$

- Q32. Can you name two groups or individuals most likely to win government contracts in the town?

- $1=$ Yes, can cite at least two groups or individuals

$-2=$ Yes, can cite a group or individual

$-3=$ No, cannot cite

- Don't know

Q32A. Write the name of the groups or individuals who are susceptible to win the government contracts in the town?

\section{H??: The capacity of the CSO - technical and social capital ( $n$ )}

- Q33. Is your group registered with the state? That is, does the group have a receipt?

- Yes

- No

\section{H3a: Legibility}

- Q34. What percentage of your members can read and write in French?

\section{H3b: Literacy/Political Knowledge}

- Q35. Do you know how to read or write in French?

- Read and write

- Read only

- Write only

- None

- Q35A. Do you follow the news in French?

$-1=$ Yes 
$-2=$ No

- Q35B. If yes, by which mode of communication?

- $\mathrm{Q} 35 \mathrm{~B} 1.1$ = SMS

- Q35B2. 2 = Phone call

- Q35B3. 3 = Radio

- Q35B4. 4 = Internet (social media)

- Q35B5. 5 = Internet (email)

- Q35B6. 6= Newspapers

- Q35B7. 7 = Television

- Q35B8. 8 = Other. Specify

- Q36. How often do you listen to the news of political parties and governance?

- 1 = Everyday

- 2 = Several times a week

- 3 = Each week

- 4 = Every few weeks

- 5 = I rarely follow news of political parties and governance

- Q37. What is the importance of working with other civil society groups to achieve your group's objectives?

-1 - Crucial

$-2=$ Very important

- 3 = Important enough

$-4=$ Not important

$-5=$ Not at all important

\section{H3c: Community Mobilization/ influence}

- Q38. To what extent do ordinary community citizens, members or not, listen when your group shares information or demands a certain form of action? On a scale of 0 to 10 (0 indicating that the community doesn't listen at all when your group shares information and 
10 indicating that the whole community listens to the sharing of information). Rate out of 10 - Q39. If your group wanted to share information or ideas with other people in the town (outside of your immediate village or neighborhood), how easily could it transmit the message or information?

$-1=$ Diffuse information very easily

$-2=$ Diffuse information easily

- 3 = A little difficult to diffuse information

- 4 = Difficult to disseminate information

- Q40. If your group wanted to convince other people from the town (outside of your immediate village or neighborhood) to support a politician, an idea or to vote for a candidate, how easily could your group do it?

$-1=$ Convince very easily

-2 = Convince easily

$-3=$ Convince easily enough

- 4 = Difficult to convince

- Q41. If your group wanted to mobilizer its own members to achieve an objective different from your daily tasks, how easily could the group mobilize its members?

$-1=$ Mobilize very easily

$-2=$ Mobilize easily

$-3=$ Mobilize easily enough

- 4 = Difficult to mobilize

- Q42. Sometimes group members tend to disagree on a lot of things, and sometimes they tend to agree on a lot of things. To what extent do the members of your group reach a collective agreement on their priorities and actions?

$-1=$ Always

-2 = Very often

$-3=$ Often 
- $4=$ Not very often

$-5=$ Never

- Q42A. Think of a time in the last two years where your group needed to advocate for its interests or negotiate with a more powerful actor. How did it make its needs heard and understood?

- Q42B. Did it succeed with this method of making its voice heard?

- Yes

$-\mathrm{No}$

\section{H3d: Internal mobilization/ coordination capacity}

- Q43. Has your group ever mobilized its members to vote or attend a rally on behalf of a political party or candidate?

- Yes

$-\mathrm{No}$

- Q44. In the last year, has your group ever mobilized to attend a public meeting?

- Yes

$-\mathrm{No}$

- Q45. In the last year, has your group ever mobilized to participate in a demonstration?

- Yes

$-\mathrm{No}$

\section{H??: The cost of social sanctions $(j)$}

- Q46. Does your group have income-generating activities?

- Yes

$-\mathrm{No}$

- Q47. If yes, what are these activities?

$-1=$ Market gardening 
$-2=$ Tontine

- $3=$ Small business

-4 = Catering

$-5=$ Other. Specify

- Q48. What is the importance of your relationship with the mayor for the functioning of your group? Would you say that it's a relationship...

$-1=$ Crucial

$-2=$ Very important

$-3=$ Important enough

$-4=$ Not important

$-5=$ Not at all important

- Q49. What is the importance of your relationships with non-member citizens for the functioning of your group? Would you say that it's a relationship..

-1 = Crucial

$-2=$ Very important

$-3=$ Important enough

$-4=$ Not important

$-5=$ Not at all important

- Q50. Do you have other sources besides membership fees of income-generating activities?

- Q51. If yes, what are these funding activities?

- Q52. What is the job of the richest member in your organization?

$-1=$ Farmer

$-2=$ Breeder

$-3=$ Fisher

- $4=$ Housekeeper

$-5=$ Trader

$-6=$ Civil servant 
- 7 = Laborer

$-8=$ Cleaning woman

$-9=$ Other. Specify

- Q53. How often do you reflect on the reactions of community members who are not part of your group before undertaking group activities?

-1 = Always

$-2=$ Very often

$-3=$ Often

$-4=$ Not very often

$-5=$ Never

- Q54. In comparison to other CSOs in your town, would you describe the wealth level of the leaders of your CSO as being:

$-1=$ Among the poorest in the town

$-2=$ Slightly poorer than other CSOs

$-3=$ About average

$-4=$ Slightly richer than other CSOs

- Among the richest in the town

- Q55. In comparison to other CSOs in your town, would you describe the wealth level of the members of your CSO as being:

$-1=$ Among the poorest in the town

$-2=$ Slightly poorer than other CSOs

$-3=$ About average

$-4=$ Slightly richer than other CSOs

- Among the richest in the town

- Q56. Do the members of your group contribute periodically to save and possibly face the economic needs of group members or mobilize members' funds to meet an urgent need from a member of the group? 
- Yes

- No

- Q57. If yes: is this the principal activity of the group?

\section{G1: Evaluation of egalitarian attitudes toward women}

- Q58. In your opinion, when money is scarce, to what extent should boys be more educated than girls?

- Always

- Very often

- Often

- Not very often

- Never

- Q59. In your opinion, if men in the community have difficulty providing for their families, to what extent should women still be able to earn money outside the home?

- Always

- Very often

- Often

- Not very often

- Very often

- Q60. In your opinion, to what extent should a husband make all of the decisions in the household about how to manage assets like farm equipment? Would you say that the husband should make all the decisions...

- Always

- Very often

- Often

- Not very often 
- Never

\section{G2: Evaluation of women's participation in decision making}

- Q61. In your family, who participates in the choices concerning sending a child to school? Is it...

- Myself

- My spouse

- Me and my spouse

- My parents

- My grandparents

- All the men in the household

- All the women in the household

- All the members of the household

- No response

- Head of the household

- Q62. In your family, who participates in the choices concerning a spouse for a son or daughter? Is it...

- Myself

- My spouse

- Me and my spouse

- My parents

- My grandparents

- All the men in the household

- All the women in the household

- All the members of the household

- No response

- Head of the household 
- Q63. In your family, who participates in the choices of whether a husband takes a spouse?

- Myself

- My spouse

- Me and my spouse

- My parents

- My grandparents

- All the men in the household

- All the women in the household

- All the members of the household

- No response

- Head of the household

- Q64. If a woman earns an income for herself, who should decide how she spends it? Is it...

- The woman

- Her spouse

- Husband and wife together

- Her parents

- Her grandparents

- All the men in the household

- All the women in the household

- All the members of the household

- No response

- Q65. When decisions are made about purchasing expensive items (for example, a household appliance, cattle or a bicycle), who in your household normally makes the decision? Is it...

- Myself

- My spouse

- Me and my spouse

- My parents 
- My grandparents

- All the men in the household

- All the women in the household

- All the members of the household

- No response

- Q66. When a member of your household needs to participate to discuss community problems, who generally participates? Is it...

- Myself

- My spouse

- Me and my spouse

- My parents

- My grandparents

- All the men in the household

- All the women in the household

- All the members of the household

- No response

- Head of the household

- Q67. When decisions are made concerning the work that women and girls in the household can do, who in your household normally makes the decision? Is it...

- Myself

- My spouse

- Me and my spouse

- My parents

- My grandparents

- All the men in the household

- All the women in the household

- All the members of the household 
- No response

- Head of the household

- Q68. When decisions are made about whether or not to borrow money from others, who in your household normally makes the decision? Is it...

- Myself

- My spouse

- Me and my spouse

- My parents

- My grandparents

- All the men in the household

- All the women in the household

- All the members of the household

- No response

- Head of the household

- Q69. When decisions are made about how much to save from household income, who in your household normally makes the decision? Is it...

- Myself

- My spouse

- Me and my spouse

- My parents

- My grandparents

- All the men in the household

- All the women in the household

- All the members of the household

- No response

- Head of the household

- Q70. How many times do you travel outside of the village (town) each month? Would you 
say that it's:

- Several times per week

- Biweekly

- Weekly

- Every two weeks

- monthly

- Quarterly

- Twice per year

- Once per year

\section{Overview of the Three Treatments:}

We have three treatments to pilot: T1, T2, and T3. For each of the three, we indicate what the individual who receives the treatment is read, and what other individuals are read.

\section{Treatment 1 (T1): Prime Group Importance}

Prior to reading the vignette, those receiving T1 we will receive the following prime.

We conducted a survey of citizens in order to make a list of the most important non-state organizations in 40 different communes in Mali. These are groups that stand out in their capacity to represent and help citizens, and which thus serve a critical function in Malian society. In order to identify such groups in your commune, we first talked to well-connected citizens from your area. We asked them to name the most active and influential CSOs in (name commune of CSO). You were named by these respondents as one of the most important CSOs operating in (name location). We are therefore eager to hear your surely very helpful and informative views.

\section{Manipulation Check Questions:}

1. QM1. How useful do you think your CSO is to typical / ordinary citizens in your community who have concerns or needs?

- Extremely useful 
- Very useful

- Moderately useful

- Sometimes useful

- Rarely useful

- Never useful

2. QM2. To what extent do you personally feel that your CSO is considered and influential, compared to other CSOs, among the typical / ordinary citizens of your community? On a ten-rung ladder, where the bottom rung indicates that the CSO is among the least regarded and most influential, and the top rung indicates that the CSO is among the most valued and influential, where do you think your CSO is located? Rate out of 10

- $1,2, \ldots, 9,10$

\section{Vignette:}

Usually, the transfers your local government gets from the national budget are based on things like population size and poverty level. However, there is a new program being planned for your commune where your local government can get a bonus payment of 5 million CFA, in addition to the standard transfer of about 30 million CFA, if it spends its money well in the previous year-that is, if it uses it for the intended purpose of providing services to citizens. The program will be piloted in your commune and several others for 5 years, and then brought to additional communes by the national government if successful. To determine how money is spent, bureaucratic agencies like the Ministry of Education and Ministry of Health will ask their local representatives to measure how well the government has been spending its money on infrastructure in these areas and whether services are actually being provided. However, civil society groups like yours often also have additional insights to contribute to such a process. This year, your group will be given the opportunity to make a report evaluating the mayor's use of funds. This report can be negative and indicate the mayor's misuse of 
funds, or positive and indicate no such misuse

\section{Treatment 2 (T2): Psychology of Scarcity:}

- The group receiving T2 is read:

You will retain this role for just one year. A different CSO will be given the opportunity to make the report in each of the following 4 years that the program is in place. Each year, the performance bonus will be based on a combination of the bureaucratic report and the CSO report.

- The group NOT receiving T2 is read:

Your group will then continue to serve this role every year for the 5 years that the program is in place. Each year, the performance bonus will be based on a combination of the bureaucratic report and the CSO report.

Everyone is then read the below information:

Now imagine a hypothetical scenario in which a new mayor is elected in 2021. This mayor misuses the 30 million CFA that are transferred to your commune in his first year in office and only builds half as much infrastructure as he could have with the funds. Because the total budget is not known by most in the community, the mayor's decision to keep some of the money is not widely known. In order to prepare an informed evaluation, your group, as a member of civil society, would be given access to information about the funds that were received and what they were supposed to be spent on. Recall that your evaluation of the mayor's performance can be positive or negative. If it is negative, you would report on the mayor's misuse of funds and decrease the chance of getting the 5 million CFA performance bonus next year. However, doing so many send a strong signal to the mayor to reform or do better in the future. In contrast, if it is positive, this increases the chance of your mayor getting a performance bonus next year.

\section{Treatment 3 (T3): Anonymity:}


- The group receiving T3 is read:

The contents of your evaluation will be sent anonymously to the office in Bamako that decides on the performance bonus and will not be observed by the mayor or others in the commune.

- The group NOT receiving T3 is read:

The fact that you are the CSO charged with overseeing the mayor, the contents of your evaluation will be observable by the mayor and others in the commune.

\section{Post-vigntette questions}

- QC1. In reflecting on other CSOs in the town, what is the percentage (0-100) between them who would submit a negative performance report on the mayor?

- QC1A1. Cite the name of a CSO that would be particularly likely to submit a negative report. Interviewer if no response enter PDR

- QC1A2. , ̈̈ú ,Äú is which type of CSO. Is it:

- Tontine

- NGO

- GRIN

- Women's association

- Religious group

- Union

- Union

- Cooperative

- Youth Association

- Simple association

- Other. Specify

- QC1B1. Cite a type of CSO that would not be likely to submit a negative performance report on the mayor. 
- QC1B2. ,Äú , Äú is which type of CSO. Is it:

- Tontine

- NGO

- GRIN

- Women's association

- Religious group

- Union

- Union

- Cooperative

- Youth Association

- Simple association

- Other. Specify

- QC2. We know that there are a lot of considerations involved in whether you are reporting on performance of the mayor or not, as this could have both benefits and costs for you and your group. Taking all of this into account, on a scale of 0 to 10 , how likely is it that you will submit a negative performance report?

- QC3. Imagine that your group has conferred with each other and decided to issue the poor performance report. The mayor finds out and wants you to change your mind and give a good performance report. You know that your commune and mayor can get a 5,000,000 CFA bonus only if you deliver a good report. To thank you for changing your minds, the mayor would like to offer your group 100,000 CFA. Would your group now decide to give a good report? [If No, ask about 150,000 CFA, 200,000 CFA, 250,000 CFA, etc until the respondent gives an affirmative answer. If the respondent wishes to say there is no amount that they would accept, then indicate "Never," and otherwise record the lowest amount in CFA that they would be willing to accept.]

- Yes

- No 
- If ,Äúno, Äù to QC3: If the mayor offers you 200,000 CFA, would your group decide now to give a good report?

- Yes

- No

- If no to QC3A: If the mayor offers you 500,000 CFA, would your group decide now to give a good report?

- Yes

- No

- If no to QC3B: If the mayor offers you 1,000,000 CFA, would your group decide now to give a good report?

- Yes

- No

- If no to QC3C: If the mayor offers you 2,000,000 CFA, would your group decide now to give a good report?

- Yes

- No

- QC4. Sometimes the funds the mayor receives can benefit an officer or a citizen who is a member of a civil society group and sometimes not. How much of the 5,000,000 CFA bonus do you think the mayor would be likely to spend in a way that benefits you or your CSO members personally?

- QC5. When the interests of politicians and those of citizens conflict, how important do you feel that your group should be seen as an advocate for citizens? On a scale of 0 to 10 , where 0 is if the group is always on the side of the politicians and 10 is if it is always on the side of the citizens, where is the group located?

- QC6. Does whether your group opposes the corrupt mayor improve or degrade your reputation in the community?

- Ameliorates 
- No impact

- Degrades

- Don't know

- QC7. If yes why and how?

- QC8. Would the members of your group tend to agree on whether or not to express their objections, or would they be divided? Please tell me where your group is knowing that, 1 if members strongly disagree and 5 if they agree, how much you think they would agree or disagree. Scale from 1 to 5 (5 in total agreement)

- QC9. Sometimes group members disagree with leaders. If the group members do not agree with the leaders, what is the probability that the leadership will change its position, 1 indicating that there is no chance of change at all, and 5 indicating certainty of change? Scale from 1 to 5 ( 5 = certainty)

- QC10. Would other groups in your community tend to agree with your group's choice on whether or not to express their objections? Do you think other bands would strongly agree, agree, no opinion, disagree or totally disagree with the choice of your group on whether or not to express the objections?

- Strongly agree

- Agree

- No opinion

- Disagree

- Totally disagree

- QC11. Would you be more or less likely to register your objections if other groups in your community could also register his objections?

- More likely if other groups could voice their objections

- Independent of other groups

- Less likely if other groups could voice their objections

- Don't know 
- No response

- QC12. Explain your response, why are you?

- QC13. In order for your CSO to fulfill this role, it must prepare a CSO report assessing the use of the funds. On a scale from 0 to 10,0 indicating that you do not think your group would be able to prepare such a report, and 10 indicating that your CSO would have the full technical capacity to produce such a report, what is the probability that your CSO is able to prepare an adequate report? Probability out of $10(10=$ full capacity $)$

- QC14. Would you be more likely to report a bad performance to:

- Your town leader

- An independent office in Bamako

- A local bureaucrat

- An NGO

- QC15. Which local leader, government official or agency would you trust most to handle your objections to the good [bad] performance report (if any)?

- QC16. What is the easiest way for you to communicate objections, if you want to report any ,Äì for example. in person, phone, internet, text?

- Text

- Phone calls

- Radio

- Internet (social media)

- Internet (email)

- Newspaper

- Television

- QC17. Is it important to you that the performance reports be shared with the citizens?

- Crucial

- Very important

- Important enough 
- Not important

- Not at all important

- QC18. In the affirmative, how would you wish that this information be provided?

- By radio

- By village assembly

- Town reunion

- Other/ Specify

- QC19. Are there certain CSOs that tend to be favored or closer to the mayor's office than others?

- Yes

- No

- QC20. If yes, cite (name) these organizations?

- QC21. If yes, what are the types of these organizations? ÔÇß

- Tontine

$-\mathrm{NGO}$

- GRIN

- Women's association

- Religious group

- Union

- Cooperative

- Youth association

- Simple association

- Other

- QC22. Do you think that your organization is a member of the mayor's group?

- Yes

$-\mathrm{No}$

- QC22. Why or why not? 
- QE10. According to you, who is responsible for this research project? 